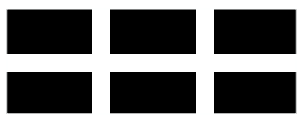

THE WILLIAM DAVIDSON INSTITUTE AT THE UNIVERSITY OF MICHIGAN BUSINESS SCHOOL

\title{
Official Regulations and the Shadow Economy: A Labour Market Approach
}

\author{
By: Maxim Bouev
}

William Davidson Working Paper Number 524

December 2002 


\title{
Official Regulations and the Shadow Economy: A Labour Market Approach
}

\author{
Maxim Bouev \\ St.Antony's College \\ Oxford OX2 6JF \\ UK \\ maxim.bouev@sant.ox.ac.uk
}

December 1, 2002

\begin{abstract}
This work revisits the role of regulations in emergence of the shadow economy. In particular, it supplements the previous theoretical research that mainly ignored the fact that the decision to "go underground" is essentially a result of both employers and employees interacting in the labour market. We adapt a job search approach (see, e.g., Acemoglu, 2001) to model a transitional economy with an informal sector. We apply and develop the idea first documented inter alia by Loayaza (1996) that there are two types of regulations that influence the size of the informal labour market through two different channels. Red tape and bureaucratic extortion (bribing) make starting a new business officially a not very attractive option and can lead new firms to the informal sector. On the other hand, taxes and redundancy pay make official firms offer lower wages which drives potential employees away into underground jobs. Depending on various combinations of policy parameters equilibria with different share of the informal economy are possible. The paper draws conclusions regarding the role of unemployment benefits, taxes and formal sector non-wage benefits in reducing the size of the informal economy. Policy implications are offered.
\end{abstract}

\section{Preliminary version}

JEL classification: H26, J41, J42, J64, O17.

Keywords: informal economy, labour markets, corruption, regulations, search models

\footnotetext{
${ }^{0}$ I am grateful to Margaret Stevens for helpful discussions of earlier versions of this paper and developments at her suggestion. Also I am thankful to Ekaterina Vostroknoutova for introduction in the topic, to all participants of the Gorman Workshop in Oxford, May 2002, for their helpful comments, and, particularly, to Phurichai Rungcharoenkitkul for his remarks on welfare issues. Equally, I indeed appreciate Sara Roberts' general sagacity. I am indebted to N M Rothschild \& Sons Ltd., London, for their financial help, without which the research would not be possible. Other usual caveats apply. Comments are welcome.
} 


\section{Non-technical summary}

An increase in the size of informal sectors all over the world has been recently noticed in a number of studies (Schneider, 2001a,b). Many authors (see, inter alia, Johnson et al, 2000) have reached an agreement that it is mainly an increasing burden of taxation, social security contributions and excessive state regulatory activities combined with labour market restrictions that have heavily contributed to growth of underground economies. Interestingly, the growth of the informal economy is accompanied by an increase in the size of underground labour markets. A large body of previous theoretical research, however, has mainly ignored the fact that the decision to "go underground" is essentially a result of both employers and employees interacting in the labour market. In particular, workers while being attracted by possible tax free unofficial earnings still have a natural tendency to land a formal job as it can be the only way to become eligible for various social security payments in case of acquired disability, retirement, etc. The literature generally misses out on this aspect.

Our work does not let sleeping dogs lie and revisits the role of regulations in emergence of the shadow economy when the labour market is taken into account. We adapt a job search approach (see, e.g., Acemoglu, 2001) to model a transitional economy with an informal sector. We apply and develop the idea first documented inter alia by Loayaza (1996) that there are two types of regulations that influence the size of the informal labour market through two different channels. Red tape and bureaucratic extortion (bribing) make starting a new business officially a not very attractive option and can lead new firms to the informal sector. On the other hand, taxes and high social security contributions make official firms offer lower wages which drives potential employees away into underground jobs. This study shows that in such a situation multiple equilibria with different share of the informal economy are possible.

The paper analyses the effect of various economic policies (including unemployment benefits, taxes, formal sector non-wage benefits, etc.) on the size of the informal economy in different equilibria. Total welfare implications are also offered. In particular, we show that in decentralised equilibrium the share of the informal sector is always ineffectively high - so the case is made for reducing the extent of the informal sector.

The search model developed in the study considers a labour market in the presence of the informal sector when productivity of formal and informal parts of the economy is the same, but there are higher barriers to entry into the formal sector. This model better describes a situation in some Eastern European economies, especially countries-successors of the former Soviet Union republics. However, one can easily draw parallels to search models built for OECD countries (e.g. Boeri and Garibaldi, 2001; Fugazza and Jacques, 2002).

The analysis of the model not only supports the widely held opinion, following from both theoretical and empirical literature (inter alia Loayaza, 1996; Fortin et al., 1997; Johnson et al., 1997; Agénor and Aizenman,1999; Sarte, 2000; Fugazza and Jacques, 2002; etc.), that higher taxes, corruption, bribery lead potential employers into the irregular economy, but also it shows that higher unemployment benefits also push off workers into informal jobs and negatively affect total surplus. 
We stress the importance of the formal sector non-wage benefits in reducing the scope of the shadow economy and raising welfare. This parallels to the result of Fugazza and Jacques (2002), who point out that individual benefits of participating in the regular sector are more desirable than a deterrence policy to cope with the informal economy. Our perhaps surprising finding is that such formal regulation as redundancy pay does not affect the allocation of jobs in the economy as its effect is totally absorbed by wages in different sectors.

In general we support the idea of Boeri and Garibaldi (2001) that policies reducing unemployment result in the reduction of the informal sector. However, contrary to their belief it is shown that in the type of equilibrium where both formal and informal sectors steadily coexist, the opposite case can be proved true as well: scaling down the informal sector can lead to a decrease in the level of unemployment.

All in all, this study suggests another view on the emergence of the irregular sector and supports Fugazza's and Jacques's (2002) argument that informality is an outcome of non-trivial interactions between various kinds of institutions (fiscal, labour market, etc.). Only through a thorough understanding of all these interactions a government can choose an effective way leading to welfare improvements. Reduction in the size of the informal sector is a general suggestion in the situation this paper is focused on. 


\section{Introduction}

An increase in the size of informal sectors all over the world has recently been the focus of a debate in many studies. The situation in OECD countries since 1960 has been analysed by Schneider $(2000,2001)$ and Schneider and Enste (2000) who point to the fact that for all countries investigated the informal economy has reached a remarkably large size. Other authors note that in most transitional countries of Eastern Europe and the former Soviet Union the irregular sectors have been growing over the last decade too (see, e.g., Johnson et al., 1997; Lackó, 2000). In such countries as Georgia, Russia and Ukraine an increase in share of the informal sector has been especially notable and it is persistent character is clearly observed. Interestingly, the growth of the informal economy is accompanied by an increase in size of underground labour markets (Schneider, 2000, 2001).

Many authors (see, inter alia, Schneider 2000, Boeri and Garibaldi, 2001) have reached an agreement that it is mainly an increasing burden of taxation, social security contributions and excessive state regulatory activities combined with labour market restrictions that have driven up the size and heavily contributed to growth of the underground economies. Tax morale, perceived fairness of the tax system are also mentioned among other causes.

There exists extensive theoretical and empirical literature concentrating on the effects of regulations on the emergence and development of the informal sector (inter alia Loayaza, 1996; Fortin et al., 1997; Johnson et al., 1997; Agénor and Aizenman,1999; Friedman at al., 2000; Sarte, 2000; etc.). However, this large body of previous research has mainly ignored the fact that the decision to "go underground" is essentially a result of both employers and employees interacting in the labour market. Perhaps, the two most notable exceptions are Boeri and Garibaldi (2001) and Fugazza and Jacques (2002) who invoke search models to qualify the links between labour market and fiscal institutions and informal activities. Although, these last two studies are undoubtedly of immense importance for deriving policy implications for such countries as Italy or Canada, they hardly properly describe the problem faced by employers and workers in some transitional countries.

Many authors point out that many emerging market economies (especially countries-successors of the former Soviet Union republics) suffer from rentseeking and bureaucratic extortion (see, e.g. Shleifer and Vishny, 1998; Frye and Zhuravskaya, 1999). At the stage of entry already, potential employers come across excessive regulations, red tape and corruption. To start a new firm, an innovator may have to obtain a great number of business, building, water and fire permits, tax documents, import licences, etc. As a result, those entrepreneurs entering the formal sector may well often be forced to pay bribes to circumvent regulations and speed up the process of enterprise registration and hiring labour. However, none of existing search models of segmented (formal/informal) labour markets take this aspect into account.

The literature also generally misses out on the importance of non-wage benefits of working in the formal sector. Even when unofficial sector offers higher 
earnings (as, for example, in Russia - see Kolev, 1998), workers still have a natural tendency to obtain a formal job as it can be the only way to become eligible for various social security payments in case of acquired disability, retirement, etc.

This work is aimed at supplementing the theoretical contribution of previous models with labour market perspective and suggesting welfare optimal policies for a regulated economy with an informal sector. We revisit the role of regulations in emergence of the informal sector and adapt a job search approach (see, e.g., Acemoglu, 2001) to model interaction of agents in a transitional economy with features mentioned above. We apply and develop the idea first documented inter alia by Loyaza (1996) that there are two types of regulations that influence the size of the informal labour market through two different channels. Red tape and bureaucratic extortion (bribing) make starting a new business officially a not very attractive option and can lead new firms to the informal sector. On the other hand, taxes and high social security contributions make official firms offer lower wages which drives potential employees away into underground jobs. Depending on various combinations of policy parameters equilibria with different share of the informal economy are possible. The paper shows that in an equilibrium, where both formal and informal economies coexist, the share of the informal sector is always inefficiently high. We draw conclusions regarding the role of unemployment benefits, taxes and formal sector non-wage benefits in reducing the size of the informal economy.

Although our model has a few similar features with Boeri and Garibaldi (2001) and Fugazza and Jacques (2002), it is notably different by endogenising wages, introducing entrance costs and formal sector non-wage benefits. Contrary to the traditional view on the informal sector as a less productive one (e.g. Agénor and Aizenman,1999; Boeri and Garibaldi, 2001), we consider sectors of equal productivity. It accords well with an important stylised fact left out by previous theoretical research: in some transitional countries both formal and informal jobs can often coexist in the same enterprises; workers can receive part of their salary in black cash - "under the table". Finally, our goal is to not merely suggest policies that can be useful for reducing the size of the informal sector but also theoretically analyse their welfare implications.

The paper is organised as follows. The next section introduces the model, derives possible equilibria and analyses effects of changes in parameters on the stable equilibrium when both formal and informal economies co-exist. Section 3 studies welfare implications, while Section 4 draws provisional conclusions.

\section{The Model of Informal Employment}

\subsection{The Main Idea}

The model developed in this section aims at capturing the influence of official regulations on the sectoral reallocation of jobs and workers in an economy with formal and informal equally productive sectors. The model is inspired by Boeri 
and Garibaldi (2001) and it adapts the approach of Acemoglu (2001) to a case where "good" and "bad" jobs represent two essentially different sectors, one of which is irregular.

The irregular sector is seen as representing productive (not rent-seeking ${ }^{1}$ ) activities that are not associated with crime or household production ${ }^{2}$ (on models of crime see Becker, 1968; Fiorentini and Peltzman, eds. 1995; on household production see Becker, 1965; Gronau, 1977). Thus, we take the approach that views informal employment as resulting from tax evasion and evasion of other costs attributed to functioning in the formal sector. An important assumption we make is that goods produced both in formal and informal sectors are perfect substitutes, while productivity of formal and informal workers is the same. We do not go along the lines of the prevalent view of the informal economy (see, for example, Agénor and Aizenman, 1999; Boeri and Garibaldi, 2001) that assumes underground jobs to be less productive and, hence, paying lower wages.

What then makes the difference between the formal and informal sector in our model? By assumption all firms producing officially have to abide by a set of rules and regulations implying additional costs to them. On the other hand, functioning informally does not involve those expenses. Jobs are not declared in order to avoid costs of functioning openly. Although such concealment of production is possible it is anyway prosecuted by officials. Each hiding firm faces some positive probability of being caught and closed as a result of government monitoring or audit.

We consider two types of rules and regulations that can have an impact on the eventual result of the reallocation of jobs and the workforce.

First, it is costs of vacancy posting in the formal sector. Opening a vacancy in either sector obviously implies some costs and can be time-consuming. However, in the formal sector registration of an enterprise/job can in fact be rather a slow business because of red tape and bureaucracy. If, in addition, the bureaucracy is corrupt the process can deliberately be slowed down in order to extort bribes from potential entrepreneurs wishing to get their businesses running quickly (see, e.g., Safavian et al, 2001). On the other hand, posting a vacancy in the informal sector can mean lower costs, for example involving only advertisement. Thus, newly established firms face a trade-off: they can either bear a higher cost (involving, e.g., paying bribes) and start functioning in the formal sector, or they can choose informal affiliation instead and pay a lower start-up price. ${ }^{3}$

\footnotetext{
${ }^{1}$ Acemoglu (1995) and Acemoglu and Verdier (1998) study the allocation of talent between productive and rent-seeking activities. Vostroknoutova (2002) extends their models to include an underground sector.

${ }^{2}$ In the literature on informal activities it is normal to distinguish between household activities, informal sector, irregular sector and criminal sector (see, for example, Thomas, 1992). While the idea behind home production and criminal activities should be obvious, one might become confused over the difference between informal and irregular sectors. Usually it is small workshops and self-employment which are regarded as the informal sector. It can also comprise home production that is traded in the market. All these activities are not illegal. The sector that we consider in this model is indeed irregular, which comprises production of legal output, but involves tax evasion and avoidance of formal regulations. However, we will use both terms "irregular" and "informal" interchangeably.

${ }^{3}$ In contrast to Boeri and Garibaldi (2001) all new jobs in the economy are not necessarily
} 
In the latter case they might be closed as soon as the tax police or similar authority gets to know about their shadow activities.

The second type of regulations that we attach a special importance in the model is taxes and fixed costs of closing a job in the formal sector (this idea is similar to Boeri and Garibaldi, 2001). It is assumed that according to the official legislation all firms supplying jobs in the formal sector have to provide some redundancy pay to their workers in case of job closure or liquidation. In principle, the amount of this payment can be seen as a function of wages. However, for keeping things simple in this paper we focus on some lump sum redundancy pay. In the informal sector firms are free to shut their businesses and fire their workers without any severance pay.

Workers in the model can either work formally or informally or be unemployed. We neglect possibilities of moonlighting, so workers can perform only one activity at a time. Aggregate labour supply is inelastic.

The economy is assumed to have free entry in each sector, so zero profit conditions and preferences of workers determine equilibrium allocation of jobs and workers in the economy in steady state. As formal and informal goods are perfect substitutes this may result in multiple equilibria (see Acemoglu, 2001) where not only one type of jobs exists but both formal and informal jobs coexist.

Here we present a basic model where all policy parameters are exogenous. We introduce a government later in Section 3.

\subsection{Matching Technology}

If there is no on-the-job search it is only the unemployed workers who look for jobs. We assume that search is undirected ${ }^{4}$, and both formal and informal vacancies have the same probability of meeting workers. Then it is the total number of vacancies that enters the matching function.

The number of job matches is given by $M(n, v)$, where $n$ is the number of workers seeking jobs (i.e. the number of unemployed) and $v$ is the number of vacancies created in the economy.

With constant returns to matching, the instantaneous probability that a vacant informal job meets a job-seeker is given by

$$
\frac{M(n, v)}{v}=M\left(\frac{n}{v}, 1\right)=q(\theta)
$$

where $\theta \equiv \frac{v}{n}$.

The first derivative of the flow rate of match for a vacancy, $q^{\prime}(\theta)$, is negative, because the greater is the value of $\theta$ the more difficult for firms it becomes to fill the job. In the matching literature $\theta$ is referred to as market tightness from the firms standpoint (see, for example, Pissarides, 2000).

Similarly, the flow rate of match for an unemployed worker is given by

${ }^{4}$ For a good model of directed search in the presence of the informal sector see Fugazza and Jacques (2002).
} 


\section{William Davidson Institute Working Paper 524}

$$
\frac{M(n, v)}{n}=M\left(1, \frac{v}{n}\right)=\alpha(\theta)=\theta q(\theta)
$$

where $\alpha^{\prime}(\theta)>0$.

When $q(\theta)$ and $\alpha(\theta)<\infty$ then matching is not instantaneous and takes some time.

We will also make the additional Inada-type assumptions that

$$
\lim _{\theta \rightarrow \infty} q(\theta)=0, \lim _{\theta \rightarrow 0} q(\theta)=\infty, \lim _{\theta \rightarrow \infty} \alpha(\theta)=\infty \text {, and } \lim _{\theta \rightarrow 0} \alpha(\theta)=0 .
$$

\subsection{Formal and Informal Jobs}

Jobs can be created in either the formal or informal sector. One job is one employee. As constant returns to matching are assumed we do not necessarily define one job as one firm. Before opening a vacancy a firm has to decide in which sector the potential match will produce and, at this point, will have to bear some costs. These costs are either $k_{f}$ or $k_{i}$, if the firm decides to open a vacancy in the formal economy or underground, respectively. These start-up costs are incurred before the firm meets its employees ${ }^{5}$ and can be thought of as job advertisement costs as well as a registration fee or bribes needed to prevent a hold-up of registration in the formal sector. ${ }^{6}$ We assume that entrepreneurs are wealthy and can meet start-up costs without resorting to external credit, etc.

All matches in the economy, either formal or informal, die at rate $\delta$. When it happens the job is destroyed while the worker becomes unemployed. As a match dies an employer in the formal sector has to provide its employee with a lump sum redundancy pay, which equals $R$. Informal employers, however, do not pay anything to workers they sack or make redundant.

Both formal and informal jobs are equally productive. Wages are paid out of the match product, $y$. In addition to wages, formal jobs have to pay a lump sum tax, $\tau$, whereas informal jobs enjoy tax evasion.

In the model it is implicitly assumed that there are some taxation authorities, e.g. tax police, whose aim is to collect taxes and reveal cases of tax evasion. So, there is an exogenous flow probability $m$ that an employer gets caught in engaging in underground business and fined by the amount $F$. When $m$ strikes the informal match is liquidated and the burden of fine is borne by the employer, not the employee. ${ }^{7}$

\footnotetext{
${ }^{5}$ This assumption is reinterpretation of the creation costs in Acemoglu (2001). There a firm incurs different costs by investing in different equipment before meeting its workers.

${ }^{6}$ Sarte (2000) builds an edogenous growth model with entry regulated by bureaucrats.

${ }^{7}$ Safavian et al. (2001) note that, in fact, tax police visits of firms are closely linked to corruption as well - regulatory inspections are positively correlated with amount of bribes payed. Interestingly, tax authorities can often change regulation without notifying entrepreneurs and then pay them a visit to obtain a fine or extorting a bribe for regulation avoidance. Evidence suggests, however, that, e.g. in Russia, firms with higher reservation profits (i.e., e.g., revenues allowing them functioning just without making losses) are less likely to be charged excessive bribe payments and, hence, less likely to be checked by monitoring bodies. Thus, in
} 


\section{William Davidson Institute Working Paper 524}

Finally, free entry is assumed both into formal and informal sectors, so firms' profits have to be equal to zero in equilibrium.

Thus, the Bellman equation ${ }^{8}$ for a formal job is

$$
r J_{f}=y-w_{f}-\tau+\delta\left(0-J_{f}-R\right)
$$

where $r$ is the flow rate of return on having the job filled (interest or discount rate), $J_{f}$ is the value of the filled formal job to the employer, and $w_{f}$ is the formal wage. The equation reads that the return to the firm on a filled job in the formal sector is equal to the difference between worker's productivity and costs, plus a potential change in value in case of the match break-up. ${ }^{9}$ We shall assume very generally that the productivity of a match, $y$, is high enough to pay wages, taxes and other costs. ${ }^{10}$

For an informal job we have

$$
r J_{i}=y-w_{i}+m\left(0-J_{i}-F\right)+\delta\left(0-J_{i}\right),
$$

where $J_{i}$ is the value of the filled informal job and $w_{i}$ is the informal wage. The equation implies that the return on a filled job in the informal sector is equal to the difference between the product of the match and worker's wage, plus a potential change in value in the case of being caught by tax authorities, plus a change in value due to the match cessation.

It is assumed that vacancy maintenance in either formal or irregular sector involves no flow costs. ${ }^{11}$ Then the Bellman equations for vacancies in formal and informal sectors are:

$$
\begin{gathered}
r V_{f}=q(\theta)\left(J_{f}-V_{f}\right), \\
r V_{i}=q(\theta)\left(J_{i}-V_{i}\right),
\end{gathered}
$$

where $q(\theta)$ is the flow rate of filling a vacancy as defined above.

our model the absence of monitoring and fines in the formal sector can be explained not only by the nature of official functioning, but it can also be interpreted in the light of Safavian et al (2001) results: higher $k_{f}$ implies higher reservation revenues in the formal sector, and, hence, the assumption of the absence of costs resulting from being monitored is reasonable.

${ }^{8}$ Hereafter we focus only on steady state values of the Bellman equations since the purpose of the paper is to analyse long-run policies that should reduce the size of the irregular sector. Out of steady states each Bellman equation in the paper should be augmented to include a first time derivative of an appropriate value function.

${ }^{9}$ We ignore a possibility of voluntary quits of workers, in which case the march breaks up as well but the employer does not pay a redundancy allowance.

${ }^{10}$ For more exact conditions see subsection 2.6.1.

${ }^{11}$ Neither in this paper do we focus on costs of maintaining vacancy affiliated with possible extortion of rents by illegal elements. This racket threat is equally likely for formal and informal firms in practice (Frye and Zhuravskaya, 1999). 
Free entry into the economy implies that it should not be possible for an additional vacancy in either sector to open and make expected net profits. Hence,

$$
\begin{aligned}
& V_{f}=k_{f} \\
& V_{i}=k_{i}
\end{aligned}
$$

That is, the condition of zero profits implies that start-up costs equal to $k_{f}$ and $k_{i}$ in formal and informal sectors, respectively, must be just recouped in equilibrium. The important assumption we make is that $k_{f}>k_{i}$, i.e. the presence of extortion costs at the moment of entry in the formal sector implies higher instant start-up costs. We shall specify more concretely the relationship between the two in section 2.6.3.

\subsection{Workers}

There is a fixed number of workers in the economy. They can be either employed in one of the sectors or unemployed.

Formal employment gives workers a monetary income, $w_{f}$, and it is also associated with some non-wage benefits $b_{f}$. The latter can be seen either as fringe benefits available in formal firms (in this case the benefits are not linked anyhow to productivity of a match) or as a flow value of future pensions, for which workers qualify while working in the formal sector. ${ }^{12}$ For simplicity, here we assume perfect substitutability between wages and the benefits.

Then the Bellman equation for formal workers looks like

$$
r E_{f}=w_{f}+b_{f}+\delta\left(E_{u}-E_{f}+R\right) \cdot{ }^{13}
$$

It reads that the return on formal employment is equal to the wage income plus non-wage benefits plus a change in unemployment in case of the match break-up. The latter brings the worker redundancy remuneration $R$.

Informal employment brings in wage $w_{i}$, but does not provide any benefits akin to those in the formal sector:

$$
r E_{i}=w_{i}+(\delta+m)\left(E_{u}-E_{i}\right)
$$

That is, the return on informal employment is equal to the wage income plus a potential change into unemployment as a result of either the match cessation or job closure due to tax evasion detected by the authorities.

\footnotetext{
${ }^{12}$ Also, following the tradition of literature on informal economies (e.g. Loayaza, 1996; Johnson at al., 1997) one can interprete $b_{f}$ as some public good access to which is only possible through official employment.

${ }^{13}$ We neglect the impact of income taxes on the value of being employed in formal sector (on unimportance of taxes for sector choice see, e.g., Lemieux et al., 1994).
} 
Finally, the Bellman equation for unemployed is

$$
r E_{u}=b_{u}+\alpha(\theta)\left(\phi\left(E_{f}-E_{u}\right)+(1-\phi)\left(E_{i}-E_{u}\right)\right)
$$

where $b_{u}$ is the unemployment benefit, $\phi$ is the probability of meeting a formal vacancy, $0<\phi<1$, and $\alpha(\theta)$ is the flow rate of finding a job in either sector. The equation says that the return on being unemployed equals unemployment compensation plus a potential change into employment in one of the sectors.

\subsection{Wages}

Wages in the model are determined through a wage bargaining process with the bargaining power of workers, $\beta$, given exogenously and such that $0<\beta<1$. Then the celebrated Nash (1950) bargaining solution implies:

$$
\begin{aligned}
& (1-\beta)\left(E_{f}-E_{u}\right)=\beta\left(J_{f}-V_{f}\right), \\
& (1-\beta)\left(E_{i}-E_{u}\right)=\beta\left(J_{i}-V_{i}\right) .
\end{aligned}
$$

It should be noted that the Nash solution in this case assumes that the threat (reservation) points for employers and employees are represented by the value of unfilled vacancy in an appropriate sector and the value of unemployment, respectively. This implies that bargaining actually takes place before the consummation of a match, but after a producer has opened a vacancy. Thus, firms are assumed to commit to wages over which the consensus was reached: they cannot change the contract once a worker gets employed. ${ }^{14}$

\subsection{Steady State Equilibria}

An equilibrium in the model is characterised by the labour market tightness, $\theta$, a probability of finding a formal job, $\phi$, and by value functions $J_{f}, J_{i}, V_{f}, V_{i}, E_{f}$, $E_{i}$, and $E_{u}$, such that equations (1)-(11) are all simultaneously satisfied. As we assumed undirected search, in steady state both formal and informal vacancies meet workers at the same rate and both types of jobs are accepted.

Acemoglu (2001) shows that in a similar model under assumptions of perfect substitutability of formal and informal goods, multiple equilibria are possible. Following the similar lines of analysis we show here that it can be possible in our model too.

\footnotetext{
${ }^{14}$ This specification of bargaining can lead to inefficiencies of equilibrium. If it is assumed that firms are risk neutral in our economy, then the flat wage profiles, to which firms commit during bargaining are not optimal. Acemoglu and Shimer (1999a) point out that in such a case an optimal strategy would be to offer large signing bonuses and then hold workers to their reservation wages. This would let risk-neutral firms bear optimally the risk of future random separations resulting in our model from job cessation and the governmental audit of informal employers.
} 


\subsubsection{Zero profit conditions}

Solving (1) and (2) for $J_{f}$ and $J_{i}$ we arrive at

$$
\begin{gathered}
J_{f}=\frac{y-w_{f}-\tau-\delta R}{\pi}, \\
J_{i}=\frac{y-w_{i}-m F}{\rho},
\end{gathered}
$$

where $\pi=r+\delta$ and $\rho=r+\delta+m$ are the effective discount rates in formal and informal sectors, respectively.

Substituting these solutions together with conditions (5) and (6) for (10) and (11), and combining the results with equations (7) and (8), simple algebra gives

$$
\begin{gathered}
w_{f}=\beta S_{f}+(1-\beta) r E_{u}-\left(b_{f}+\delta R\right), \\
w_{i}=\beta S_{i}+(1-\beta) r E_{u},
\end{gathered}
$$

where $S_{f}=y+b_{f}-\tau-k_{f} \pi$ and $S_{i}=y-m F-k_{i} \rho$ - are total flow surpluses of a match in the formal and informal economies, respectively. These equations imply that the worker gets share $\beta$ of the surplus of a match plus $(1-\beta)$ times his outside option. In the case of formal employment the worker's wage is corrected for non-wage benefits, $b_{f}$, and probable redundancy payment, $R$.

Having obtained expressions for $w_{f}$ and $w_{i}$, by using equations (12) and (13) together with (3), (4), we can define two profit functions for the formal and informal sector respectively:

$$
\begin{array}{r}
\Pi_{f}(\theta, \phi)=V_{f}-k_{f}=q(\theta) \frac{(1-\beta)\left(y+b_{f}-\tau-r E_{u}(\theta, \phi)\right)}{\pi(r+q(\theta)(1-\beta))}-k_{f}, \\
\Pi_{i}(\theta, \phi)=V_{i}-k_{i}=q(\theta) \frac{(1-\beta)\left(y-m F-r E_{u}(\theta, \phi)\right)}{\rho(r+q(\theta)(1-\beta))}-k_{i} .
\end{array}
$$

Then the zero profit conditions (5) and (6) can be reexpressed as $\Pi_{f}(\theta, \phi)=0$ and $\Pi_{i}(\theta, \phi)=0$, or

$$
q(\theta) \frac{(1-\beta)\left(y+b_{f}-\tau-r E_{u}(\theta, \phi)\right)}{\pi(r+q(\theta)(1-\beta))}=k_{f},
$$




\section{William Davidson Institute Working Paper 524}

$$
q(\theta) \frac{(1-\beta)\left(y-m F-r E_{u}(\theta, \phi)\right)}{\rho(r+q(\theta)(1-\beta))}=k_{i} \cdot{ }^{15}
$$

Each of the equations (18) and (19) defines $\theta$ as a function of $\phi$ and parameters of the model, $k_{f}, k_{i}, \beta, r, \delta, b_{f}, b_{u}, \tau, m, F$. To close the circle we need to analyse properties of $E_{u}(\theta, \phi)$.

\subsubsection{The value of being unemployed}

The value of being unemployed follows from (9) and equals

$$
E_{u}(\theta, \phi)=\frac{b_{u} \pi \rho+\alpha(\theta) \beta\left(\phi \rho S_{f}+(1-\phi) \pi S_{i}\right)}{r(\alpha(\theta) \beta((1-\phi) \pi+\phi \rho)+\pi \rho)} .
$$

For the function $E_{u}(\theta, \phi)$ it can easily be verified that it is continuous and bounded by $\left[\frac{b_{u}}{r}, \max \frac{1}{r}\left(S_{f}, S_{i}\right)\right]$. Also, it is strictly increasing in $\theta$ provided that $y$ and $b_{f}$ are big enough. ${ }^{16}$ The intuition behind this result is straightforward: the value of being unemployed is increasing in market tightness, as it becomes easier to find a job. In contrast, without additional assumptions about the parameters of the model $E_{u}(\theta, \phi)$ cannot be shown to be increasing or decreasing in $\phi$ everywhere. The sign of the derivative $\frac{\partial E_{u}(\theta, \phi)}{\partial \phi}$ hinges upon the relative value of employment in formal and informal sectors, $E_{f}$ and $E_{i}$, respectively. In particular, whenever $E_{f}$ is greater than $E_{i}, \frac{\partial E_{u}(\theta, \phi)}{\partial \phi}$ is positive, and negative otherwise. This result implies that the value of being unemployed rises whenever does the proportion of vacancies posted in the sector, the value of employment in which is higher.

Various combinations of model's parameters define a relative value of $E_{f}$ and $E_{i}$. It turns out, however, that two effects are of central importance here. First, it is the effect of relative match duration in a particular sector, and, second, the effect of the relative size of the surplus in the same sector compared to the other sector. Thus, considering ratios of the two effective discount rates, $\frac{\rho}{\pi}$, and relative values of surpluses in the two sectors less unemployment benefits, $\frac{S_{f}-b_{u}}{S_{i}-b_{u}}$, is enough to describe cases when $E_{f}>E_{i}$ and $E_{f}<E_{i}$. In Fig.1 we

\footnotetext{
${ }^{15}$ Alternatively, we can reexpress the two zero profit conditions using the notation for match surpluses introduced above:

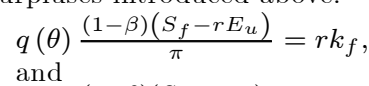$$
q(\theta) \frac{(1-\beta)\left(S_{i}-r E_{u}\right)}{\rho}=r k_{i} \text {. }
$$

${ }^{16}$ In particular, to guarantee $\frac{\partial E_{u}(\theta, \phi)}{\partial \theta}>0$ we must reasonably claim that at least $y+b_{f}>$ $\tau+k_{f} \pi+b_{u}$, i.e. the product of a match, $y$, plus the public good, $b_{f}$, are at least as large as to pay all the flow costs of functioning in the formal sector and the wage equal to the reservation value, $b_{u}$. This condition implies that $E_{f}>E_{u}$ holds. Analogously, to insure $E_{i}>E_{u}$, we must guarantee $y>m F+k_{i} \rho+b_{u}$. Otherwise, whenever any of these conditions is not met, an appropriate sector simply does not exist.
} 
put $\frac{S_{f}-b_{u}}{S_{i}-b_{u}}$ on the horizontal axis and measure $\frac{\rho}{\pi}$ on the vertical axis. The figure demonstrates three regions that we shall concentrate on in the further analysis. $^{17}$

In region 1 in Fig. 1 the formal sector surplus is greater than its informal counterpart, i.e., $\frac{S_{f}-b_{u}}{S_{i}-b_{u}}>1$, and the ratio of the two effective discount rates, $\frac{\rho}{\pi}$, is greater than the inverse of the ratio of two surpluses (shown by a downward sloping curve in the figure). The latter constraint is not binding, though, but what matters is that in this region the formal sector provides higher income to workers and employers than the informal sector does. At the same time the duration of a formal match is longer than that of the informal match: by assumption the formal discount rate is not higher than its counterpart in the informal sector, $\pi \leq \rho$. These combinations of parameters unambiguously imply that $E_{f}>E_{i}$ and, thus, $\frac{\partial E_{u}(\theta, \phi)}{\partial \phi}>0$.

The inverse combination of parameters defines region 3 in Fig.1. Now it is the informal sector that allows workers and employers enjoy a higher surplus, i.e. $\frac{S_{f}-b_{u}}{S_{i}-b_{u}}<1$. The informal income thus generated is so big that its effect on matching agents is not even counterbalanced by the fact that the effective discount rate in the informal sector is still higher than in the formal one: although $\frac{\rho}{\pi}>1$, in this region the ratio is lower than the inverse of the ratio of the two surpluses, $\frac{\rho}{\pi}<\frac{S_{i}-b_{u}}{S_{f}-b_{u}}$. Thus, here we clearly have $E_{f}<E_{i}$, while $\frac{\partial E_{u}(\theta, \phi)}{\partial \phi}<0$.

Finally, in region 2, on the one hand, the informal sector offers a higher surplus, $\frac{S_{f}-b_{u}}{S_{i}-b_{u}}<1$, but, on the other hand, its effect may be counterbalanced by a higher effective discount rate in the irregular economy: $\frac{\rho}{\pi}>\frac{S_{i}-b_{u}}{S_{f}-b_{u}}$. This implies that both cases $E_{f}>E_{i}$ and $E_{f}<E_{i}$, and hence $\frac{\partial E_{u}(\theta, \phi)}{\partial \phi}>0$ and $\frac{\partial E_{u}(\theta, \phi)}{\partial \phi}<0$, are possible depending on which factor has a greater influence on agents in the economy.

Proposition 1 There exists some threshold value of the market tightness $\bar{\theta}$, defined by the parameters $k_{f}, k_{i}, \beta, r, \delta, b_{f}, b_{u}, \tau, m, F$, and parameters of the matching function, such that for parameter values satisfying conditions in region 2 , Fig.1, and for any $\theta>\bar{\theta}$ the derivative $\frac{\partial E_{u}(\theta, \phi)}{\partial \phi}$ is negative, and for any $\theta<\bar{\theta}$ it is positive.

The proof of the proposition above is relegated to Appendix A.

The two effects of relative match duration and the relative size of two surpluses considered above prove to be very important not only for the sign of $\frac{\partial E_{u}(\theta, \phi)}{\partial \phi}$, but also for the type of equilibrium that results in the model. We elaborate on this importance in the subsection that follows.

\subsubsection{Finding equilibria}

If there exists an equilibrium with both formal and informal jobs then both formal and informal profits must be equal to zero at the equilibrium point.

\footnotetext{
${ }^{17}$ Note, by assumption of the model $\rho \geq \pi$ and, thus, all possible cases are confined to the shaded area in Fig.1.
} 
That is, the equations (18) and (19) are simultaneously satisfied. Alternatively, there can exist equilibria with only one type of jobs. In that case, profits in one of the sectors would be negative and only one of the equations (18) and (19) would hold.

Two loci The two zero profit conditions (18) and (19) define two loci of formal and informal jobs in $(\theta, \phi)$-plane. Both must be evaluated with the expression for $E_{u}(\theta, \phi)(20)$ substituted in.

By using simple algebra and invoking the implicit function theorem it can easily be verified that the locus of formal jobs (18) has a slope

$$
\left.\frac{\partial \theta}{\partial \phi}\right|_{f}=\frac{\frac{\partial E_{u}(\theta, \phi)}{\partial \phi}}{\frac{\partial q(\theta)}{\partial \theta} \frac{k_{f} \pi}{q^{2}(\theta)(1-\beta)}-\frac{\partial E_{u}(\theta, \phi)}{\partial \theta}} .
$$

Since $\frac{\partial E_{u}(\theta, \phi)}{\partial \theta}$ is always positive, whereas $\frac{\partial q(\theta)}{\partial \theta}<0$, it is obvious that the denominator is negative. Then the slope of the locus of formal jobs has a sign opposite the sign of $\frac{\partial E_{u}(\theta, \phi)}{\partial \phi}$.

Analogously, the slope of the locus of informal jobs (19) in $(\theta, \phi)$-plane is

$$
\left.\frac{\partial \theta}{\partial \phi}\right|_{i}=\frac{\frac{\partial E_{u}(\theta, \phi)}{\partial \phi}}{\frac{\partial q(\theta)}{\partial \theta} \frac{k_{i} \rho}{q^{2}(\theta)(1-\beta)}-\frac{\partial E_{u}(\theta, \phi)}{\partial \theta}},
$$

which, again, by the same token, has a sign opposite the sign of $\frac{\partial E_{u}(\theta, \phi)}{\partial \phi}$.

Remark 2 Both the locus of formal jobs (18) and the locus of informal jobs (19) have slopes of the same sign.

For different combinations of parameters represented by regions 1-3 in Fig.1, the two loci will be either positively or negatively sloped. We consider this issue further in the next subsection.

If the two loci intersect at some $\theta^{*}$ and $0<\phi^{*}<1$, then the pair $\left(\theta^{*}, \phi^{*}\right)$ is an interior equilibrium. Otherwise, only corner equilibria of the types $(*, 0)$ or $(*, 1)$ are possible.

Existence, uniqueness and stability of equilibria When analysing the sign of the derivative $\frac{\partial E_{u}(\theta, \phi)}{\partial \phi}$ above, we rested the discussion of possible cases on relation between the ratio of the two effective discount rates, $\frac{\rho}{\pi}$, and the surpluses in two sectors, $\frac{S_{i}-b_{u}}{S_{f}-b_{u}}$. As $\frac{\partial E_{u}(\theta, \phi)}{\partial \phi}$ determines slopes of the two loci defined in the preceding subsection, the relative effects of match duration in a particular sector, $\frac{\rho}{\pi}$, and of the surplus size in there, $\frac{S_{i}-b_{u}}{S_{f}-b_{u}}$, directly affect the type of equilibrium outcome, and particularly the resulting value of equilibrium market tightness. But what happens to be central to the problem of existence 
and stability of equilibrium is the relative effect of flow value of start up costs, $\frac{\rho k_{i}}{\pi k_{f}}$ compared to the relative effect of the surplus size, $\frac{S_{i}-b_{u}}{S_{f}-b_{u}}$. If the two effects complement each other the model generates either a unique equilibrium with formal jobs only or an equilibrium with informal jobs only. If the two effects are counterbalancing an interior equilibrium with both types of jobs becomes possible.

Fig.2 shows six non-overlapping regions A-F, each of which corresponds to various combinations of parameters and represents a particular equilibrium type. To bear a resemblance to Fig.1, we measure $\frac{\rho}{\pi}$ on the vertical axis and $\frac{S_{f}-b_{u}}{S_{i}-b_{u}}$ on the horizontal axis, and show the inverse relation, $\frac{S_{i}-b_{u}}{S_{f}-b_{u}}$, as a dashed curve. Above the latter is the solid curve $\frac{k_{f}}{k_{i}} \frac{S_{i}-b_{u}}{S_{f}-b_{u}}$. This is obtained from the inverse ratio of the two surpluses, $\frac{S_{i}-b_{u}}{S_{f}-b_{u}}$, by multiplying it by the ratio of the start-up costs in two sectors, $\frac{k_{f}}{k_{i}}$, which is always greater or equal to 1 by assumption. The curve $\frac{k_{f}}{k_{i}} \frac{S_{i}-b_{u}}{S_{f}-b_{u}}$, as well as straight lines $\frac{k_{f}}{k_{i}}=1$ and $\frac{S_{f}-b_{u}}{S_{i}-b_{u}}=1$ (or, equivalently $S_{f}=S_{i}$ ), define boundaries of regions A-F. It turns out that an interior equilibrium does exist in two regions $\mathrm{A}$ and $\mathrm{D}$, while under parameters' values satisfying restrictions corresponding to regions B, C, E, and F in Fig.2 the two loci do not intersect. There the resulting equilibrium will consist of one type of jobs only. Now we can move on to discussing uniqueness and stability of equilibria in each of the regions A-F.

Region A. In region A in Fig. $2 \frac{\partial E_{u}(\theta, \phi)}{\partial \phi}>0$ so that expressions (21) and (22) are negative, and both loci are downward sloping. Restrictions on parameter values in this region imply that the formal sector surplus is greater than its informal counterpart, $\frac{S_{f}-b_{u}}{S_{i}-b_{u}}>1$, while the ratio of flow values of start-up costs is lower than the inverse ratio of surpluses, $\frac{\rho k_{i}}{\pi k_{f}}<\frac{S_{i}-b_{u}}{S_{f}-b_{u}}$. This implies that, on the one hand, the formal sector attracts employers and employees by big potential income resulting from a higher value of the formal surplus, but, on the other hand, employers shrink from opening too many vacancies formally as they face higher flow value of entry costs, $\pi k_{f}$, to recoup later on. In this situation, it is easy to verify that the locus of formal jobs (18) and the locus of informal jobs (19) have an intersection point for some $0<\phi^{*}<1$ and, that the former locus is flatter than the latter locus in some neighbourhood of that intersection point. So the locus of formal jobs crosses the locus of informal jobs from below, as shown in Fig.3. Given that $\left.\frac{\partial \Pi_{f}(\theta, \phi)}{\partial \theta}\right|_{\Pi_{f}(\theta, \phi)=0}<0$ and $\left.\frac{\partial \Pi_{i}(\theta, \phi)}{\partial \theta}\right|_{\Pi_{i}(\theta, \phi)=0}<0$ (see Appendix A for proof), i.e. profits both in formal and informal sectors decrease in market tightness along the appropriate $\operatorname{loci}^{18}$, the interior equilibrium is not stable in this case. At the same time there exist two other stable equilibria where only one of the sectors exists.

Region B. In region B the surplus in the informal sector is greater than the surplus in the formal sector, $\frac{S_{f}-b_{u}}{S_{i}-b_{u}}<1$, while flow values of the entry costs are still such that $\rho k_{i}<\pi k_{f}$. That is, workers and employers not only get higher surplus if match informally, but the latter need to recoup lower start-up

${ }^{18}$ These conditions hold for all the cases in the model. 
expenses if operate underground. In this region the locus of informal jobs lies above the locus of formal jobs and the resulting equilibrium with informal jobs alone is stable (Fig.4).

Region C. The situation corresponding to region $\mathrm{C}$ is similar to that in region $\mathrm{B}$. However, in region $\mathrm{C} \rho k_{i}>\pi k_{f}$, i.e. the flow value of informal entry costs is higher than that of the formal entry costs. At the same time, this negative news for informal employers is more than compensated by the higher surplus that informal matches bring in: $\frac{\rho k_{i}}{\pi k_{f}}<\frac{S_{i}-b_{u}}{S_{f}-b_{u}}$. So, again the result is a stable equilibrium without formal jobs (Fig.4). ${ }^{19}$

Regions $\mathbf{E}$ and $\mathbf{F}$. These two regions mirror the cases for regions B and $\mathrm{C}$ just considered. There, however, only an equilibrium with formal jobs results (Fig.5) as not only the formal sector surplus is greater than its informal counterpart, $\frac{S_{f}-b_{u}}{S_{i}-b_{u}}>1$, but also the ratio of flow values of entry costs is such that $\frac{\rho k_{i}}{\pi k_{f}}>\frac{S_{i}-b_{u}}{S_{f}-b_{u}}$. The latter inequality implies that the relation between flow values of start-up costs never compensates the difference between surpluses in the two sectors. It can be the case that $\rho k_{i}>\pi k_{f}$ (region E), or $\rho k_{i}<\pi k_{f}$ (region F), but the effect of the greater formal surplus always prevails on employers and workers to match formally.

Region D. Finally, in region D in Fig.2 restrictions on parameters suggest that the formal surplus is smaller than the informal surplus, $\frac{S_{f}-b_{u}}{S_{i}-b_{u}}<1$, while the ratio of flow values of entry costs is greater than the inverse ratio of surpluses, $\frac{\rho k_{i}}{\pi k_{f}}>\frac{S_{i}-b_{u}}{S_{f}-b_{u}}$. This implies that, on the one hand, the irregular sector is more appealing to employers and workers due to higher potential income, but, on the other hand, employers hold back from opening vacancies informally as they face a higher flow value of start-up costs, $\rho k_{i}$, to regain after entry. ${ }^{20}$ By analogy with the case of region A, it is easy to verify that the locus of formal jobs (18) and the locus of informal jobs (19) have an intersection point for some $0<\phi^{*}<1$, i.e. an interior equilibrium with both types of jobs exists. For parameter values in region $\mathrm{D}$ the formal jobs locus is steeper than its informal counterpart in some neighbourhood of an interior equilibrium $\left(\theta^{*}, \phi^{*}\right)$. In this region $\frac{\partial E_{u}(\theta, \phi)}{\partial \phi}$ can be either negative or positive, as region D in Fig.2 is a subarea of region 2 in Fig.1.

\footnotetext{
${ }^{19}$ In both regions $\mathrm{B}$ and $\mathrm{C}$ depending on the values of parameters the economy can be either above or below the dashed curve in Fig.2. Then, the sign of $\frac{\partial E_{u}(\theta, \phi)}{\partial \phi}$ can either be positive or negative, and, hence, both loci of formal and informal jobs can be either negatively or positively sloped. However, it does not change the essence of the result: the informal locus lies above the formal one, i.e. when formal jobs just break even, informal matches make positive profits. Fig. 4 corresponds to the situation when $\frac{\partial E_{u}(\theta, \phi)}{\partial \phi}>0$.

${ }^{20}$ Another way to see the trade off faced by employers in this region is to expand expressions for surpluses and analyse the resulting combination of parameters. So, e.g. $\frac{S_{f}-b_{u}}{S_{i}-b_{u}}<1$ is equivalent to $S_{f}-S_{i}=b_{f}-\tau-\pi k_{f}+m F+\rho k_{i}<0$. Since $\pi k_{f}<\rho k_{i}$ in this region, we must have $\tau-b_{f}>m F$. This implies that the negative effect of the tax rate net of formal sector non-wage benefits confronted by employers in the official part of the economy overweighs the effect of governmental audit of the informal jobs, $m F$. So, employers are tempted to run business informally. At the same time, the audit is still intensive enough to make the flow value of informal sector entry costs higher than its formal counterpart (remember, $\rho=\pi+m$ ). This squeezes informal profits and holds back informal employers.
} 
From proposition 1 we know that the sign of the derivative is negative for any $\theta>\bar{\theta}$, and positive for any $\theta<\bar{\theta}$, where $\bar{\theta}$ is some threshold value of the market tightness. Then for $\theta>\bar{\theta}$ the two loci will both be positively sloped, whereas for $\theta<\bar{\theta}$ they will be downward sloping.

Proposition 3 Let $\bar{\theta}$ be a threshold value of market tightness such that $\frac{\partial E_{u}(\bar{\theta}, \phi)}{\partial \phi}=$ 0 and $\left(\theta^{*}, \phi^{*}\right)$ be a point of an interior equilibrium in region D, Fig.2. Then $\theta^{*}$ is always less than $\bar{\theta}$.

Proof: see Appendix A.

Proposition 3 implies that if the two loci of formal and informal jobs intersect and an interior equilibrium results we can confine ourselves to the situation with a less tight labour market, i.e. $\theta<\bar{\theta}$. Then $\frac{\partial E_{u}(\theta, \phi)}{\partial \phi}>0$, the two loci have negative slopes and the formal jobs locus crosses the informal jobs locus from above: the resulting equilibrium is unique and stable (Fig.6).

\subsubsection{Summing up}

In this section we have found conditions for existence of equilibria of different types. The analysis above, in fact, implies that whenever $\frac{\partial E_{u}(\theta, \phi)}{\partial \phi}>0$, i.e. the value of being employed in the formal sector, $E_{f}$, is greater than the value of being informally employed, $E_{i}$, there always exists an equilibrium with formal jobs (regions A,D,E and F in Fig.2). At the same time there can exist equilibria with a positive proportion of informal vacancies (regions A and D). Otherwise, when $\frac{\partial E_{u}(\theta, \phi)}{\partial \phi}<0$, workers prefer irregular employment more and the only equilibrium with informal jobs results (regions B and C in Fig.2).

We have also shown that in cases when an interior equilibrium exists two effects balance each other. The first effect is the impact of surplus in a particular sector. For example, in region A, Fig.2., $S_{f}>S_{i}$. This makes informal work not attractive for employers and workers. The second effect is the impact of upfront costs that employers have to pay before opening a vacancy. So, in the same region, $\frac{\rho k_{i}}{\pi k_{f}}<\frac{S_{i}-b_{u}}{S_{f}-b_{u}}$ or $\pi k_{f}>\rho k_{i}$. This implies that potential entrants into the formal sector should be prepare to get back higher start-up costs, and this has a negative effect on attractiveness of the formal sector. Thus, the equilibrium with formal and informal sectors results as a balance of two effects. The similar reasoning is applied to analysis of the equilibrium in region D, Fig.2.

In all other regions represented in Fig.2 both effects just discussed either act in the same direction, or one never compensates another, which brings around an equilibrium with one type of jobs only.

Even when the interior equilibrium exists it can be unstable, which takes place for parameter values satisfying region A, Fig.2. By contrast, in region D the equilibrium is stable.

All in all, this analysis implies that the equilibrium proportion of formal jobs reflects relative costs and gains for workers and employers of functioning in the formal sector. Thus, it supports Loayaza (1996) and Kaufmann (1997) who 
pointed out that the ratio of reported to unreported activities depends largely on the costs and benefits of operating in each economy.

In the next section we further develop the investigation to look closely at how changes in various parameters affect the equilibrium allocation of jobs and vacancies.

\subsection{Changes in Parameters: an Impact on Job Allocation}

Now that we have established equilibrium properties of the model and discussed what they mean, we can examine how changes in parameter values affect the equilibrium outcome. We choose the case represented in Fig.6 as a basis for further analysis and as a starting point for our economy. It is obvious that this case is also the most interesting one for the purpose of our work. There in the stable equilibrium both formal and informal sectors co-exist, and a part of the economy is hidden from the view of official authorities. In other cases represented in Fig.3, 4, and 5 either only one of the sectors exists in equilibrium or the equilibrium where both sectors are present is unstable.

The equilibrium allocation of jobs in our economy depends on a number of parameters such as taxes, unemployment benefits, entry costs, etc. If one or a few of these parameters vary the equilibrium in Fig. 6 shifts to a new position. It is important to remember that many of these parameters are, in effect, policy tools in the hands of government. So, the government can often achieve a desirable allocation of jobs simply by changing a value of one of the parameters. Here we consider effects of such changes for each parameter in turn, holding other parameters of the model constant.

\subsubsection{Monitoring and fines for engagement in informal activity}

Monitoring of firms and fines for engagement in the informal business are the costs of operating in the informal sector. Suppose, first, the government decides to subsidise monitoring authorities (e.g. tax police) more generously, which results in an increase in $m$ - the variable, describing the probability that an employer gets caught working in underground business. Such a rise in $m$ leads, firstly, to a decrease of the informal surplus relative to the formal surplus, and, secondly, to an increase in the rate of death of the informal matches. The former effect has a negative impact on the profitability of underground jobs, whereas the latter has a positive externality effect: since underground firms die faster, it becomes easier to fill in vacancies for remaining shadow businesses. It is easy to verify that the overall effect of an increase in $m$ brings about an increase in the share of formal vacancies, $\phi$, as well as reduces the equilibrium value of the market tightness, $\theta$. Apart from that, it can also be shown that not only the proportion of formal vacancies increases, but the total number of formal jobs also rises, while the total number of informal jobs decreases. Moreover, the latter effect is outweighed by the former so that unemployment decreases.

A further and greater increase in $m$ can dramatically reduce the informal surplus and bring the underground sector to a halt. Such a situation will cor- 
respond to a shift from region $\mathrm{D}$ to region $\mathrm{E}$ in Fig.2, where the only possible equilibrium consists of formal jobs alone.

Instead of investing more in monitoring authorities in an attempt to shackle the shadow sector, the government may simply increase punishment for involvement in underground business. In our model, this would imply a rise in $F$.

The effect of higher $F$ is somewhat similar to that of an increase in $m$, with the exception of that the former does not affect the effective discount rate in the informal sector, $\rho$, and, thus, does not create a positive externality on informal firms competing for workers. An increase in $F$ shifts the locus of formal firms (18) up, whereas the informal jobs locus (19) then moves down. This results in an unambiguous decrease in $\theta$, while $\phi$ rises (Fig.7). The number of formal jobs increases, while the number of informal jobs drops. Unemployment is also reduced. Again, a further and greater increase in $F$ would result in a collapse of the informal sector and bring the economy in region E in Fig.2.

\subsubsection{Taxes}

Empirical literature has suggested that taxes levied in the formal sector are one of the possible reasons that drives potential employers underground as they represent one of the costs of legal production (see e.g. Johnson et al., 2000). In our model an increase in the value of lump sum taxes on formal employers, $\tau$, reduces the formal sector surplus and results in locus's of formal jobs (18) shifting down in $(\theta, \phi)$-plane, while the locus of informal jobs (19) shifts up. This implies that the equilibrium value of $\theta$ rises, whereas the equilibrium value of $\phi$ decreases (Fig.8). The number of formal jobs decreases, and the number of informal jobs rises, together with the number of unemployed.

By reasoning similar to one in the case with monitoring and fines, a substantial increase in taxes may toss the economy across from region $\mathrm{D}$ to region $\mathrm{C}$ in Fig.2 where the only stable equilibrium is the one with informal jobs alone.

\subsubsection{Unemployment benefits}

Contrary to taxes, fines and monitoring, unemployment benefits affect neither formal surplus $S_{f}$ nor informal surplus $S_{i}$. However, they still are very crucial for intersectoral job allocation.

An increase in $b_{u}$ makes both loci (18) and (19) shift down. It is straightforward to verify that $\frac{d \phi}{d b_{u}}<0$, while $\frac{d \theta}{d b_{u}}=0$ by totally differentiating (18) and (19) with respect to $\theta, \phi$ and $b_{u}$, and then solving the system of resulting equations in a stable equilibrium for $\frac{d \phi}{d b_{u}}$ and $\frac{d \theta}{d b_{u}}$. This result implies that in effect for a given $\theta$ both loci shift by the same distance, i.e. the equilibrium proportion of formal jobs, $\phi$, decreases, whereas the equilibrium value of market tightness, $\theta$, does not change. Thus, the introduction of more generous unemployment benefits leads to crowding out of formal vacancies by informal ones. This can be explained by the fact, that higher benefits raise the reservation value of workers, who can now afford to wait longer for jobs with higher pay in the informal sector and accept them more eagerly, even though they are more risky in terms 
of shorter average duration. The result also obtains that the number of formal jobs drops whereas both the number of informal jobs and unemployment rise. Again, too large an increase in unemployment benefits would flip the economy into the region $\mathrm{C}$ in Fig.2. with an equilibrium as in Fig.4.

\subsubsection{Non-wage benefits and redundancy pay in the formal sector}

One of distinctive features of our model is that we explicitly consider non-wage benefits received by formally employed workers. A change in $b_{f}$ makes the formal sector more or less attractive and affects the equilibrium outcome.

An increase in $b_{f}$, for example, will force the locus of formal jobs to shift up, as it will raise the surplus obtained in the formal sector. On the other hand, the locus of informal jobs will move down, as the equilibrium value of $G(\theta, \phi)$ increases. This results in a drop in $\theta$ and a rise in $\phi$ (Fig.7). Also the number of formal jobs rises and the number of informal jobs drops, whereas unemployment is reduced. In general, the non-wage benefits that can be thought of as either some public good provided to formally employed, or a discounted value of future pensions, are a useful instrument of bringing workers and employers back from the shadow sector. The eventual result of a substantial increase in $b_{f}$ can lead the economy to end up in region E in Fig.2, where there are no informal jobs in equilibrium.

Unlike non-wage benefits in the formal sector, the redundancy pay parameter, $R$, does not affect the equilibrium composition of jobs, and thus any changes in it will not have any effect on job allocation across sectors. This is explained by impacts of $R$ on the value of a filled job in the formal sector, $J_{f}$, and the formal wage, $w_{f}$, that cancel out each other, so that the resulting value of a formal job, $J_{f}$, does not change at all. The only visible outcome of, for example, an increase in redundancy pay, $R$, is a deepening in the gap between formal and informal wages (see (14)).

\subsubsection{Other institutional changes}

Apart from parameters representing primary policy instruments, the allocation of jobs across sectors in the model depends on relative entry costs, $\frac{k_{f}}{k_{i}}$, and the bargaining power of workers, $\beta$. These parameters reflect the institutional environment in the economy: spreading corruption and bribery, for example, increases $\frac{k_{f}}{k_{i}}$, while strengthening in a position of trade unions raises $\beta$.

Consider, for example, a decrease in $k_{f}$, which corresponds to less bribing and extortion in the formal sector. This can possibly be achieved by restructuring the bureaucracy and by better enforcement of laws cracking down on corruption. With such a decrease in $k_{f}$ the locus of formal jobs moves up, while the locus of informal jobs shifts down. The outcome is a drop in the equilibrium value of $\theta$, and an increase in the equilibrium value of $\phi$ (Fig.7). The number of formal jobs rises, whereas the number of informal jobs decreases along with the level of unemployment. On the other hand, an upsurge in corruption and rent-seeking 
in the economy would result in an increase in $k_{f}$, and hence in a rise in both unemployment and the proportion of informal vacancies and jobs.

Institutional changes leading to an increase in the bargaining power of workers, $\beta$, shift both loci of formal and informal jobs down, so that the effect on $\theta$ and $\phi$ is ambiguous. However, under certain assumptions, in particular when matching function exhibits constant returns, and the Hosios (1990) efficiency condition is met, it is possible to show that $\theta$ drops whereas $\phi$ does not change as a result of a rise in $\beta$. At the same time both numbers of formal and informal jobs decrease, while the unemployment rate rises.

\subsubsection{Results summary and notes on policies}

Table 1 summarises the effects of parameter changes considered above.

Table 1.

\begin{tabular}{|c|ccccc}
\hline An increase in & \multicolumn{5}{|c}{ Effect on } \\
\hline & $\phi$ & $\theta$ & $N$ & $I$ & $U$ \\
\hline \hline$m$ & + & - & + & - & - \\
$F$ & + & - & + & - & - \\
$\tau$ & - & + & - & + & + \\
$b_{u}$ & - & 0 & - & + & + \\
$b_{f}$ & + & - & + & - & - \\
$\beta$ & 0 & - & - & - & + \\
$k_{f}$ & - & + & - & + & + \\
$R$ & 0 & 0 & 0 & 0 & 0
\end{tabular}

By $N, I$ and $U$ we denote numbers of filled formal and informal jobs, and the number of the unemployed, respectively.

It can be seen that an increase in $m, F, b_{f}$, and/or a decrease in $\tau, k_{f}$ and $b_{u}$ reduce the share of the informal sector in the economy when measured both by the proportion of its vacancies in the total number of vacancies and by the ratio of filled informal jobs to filled formal jobs. A few provisional policy implications follow from here.

First, these results support the idea that taxes may cause businesses to flee into the shadow economy, and that a higher tax burden is associated with a higher share of the informal sector (see Johnson et al., 2000). To increase the number of formal jobs and vacancies governments should unambiguously decrease taxes, should it find the economy in a situation corresponding to Fig.6.

Second, widespread corruption, rent-seeking and bribery in an economy would also force potential employers out into underground, as can readily be seen by increasing $k_{f}$. This finding accords well with empirical studies in Eastern Europe (e.g., Friedman et al., 2000; Johnson et al, 2000). Thus, curbing corruption and bribery pays by prompting employers away from the informal sector. This result is very much in line with theoretical work by Murphy et al. (1993), Shleifer and Vishny (1998), Sarte (2000), as well as it supports findings of a more recent study by Vostroknoutova (2002).

Third, the analysis suggests that providing non-wage benefits to those formally employed is very important unless one wishes to see more matches created 
informally. Lavish formal sector benefits, $b_{f}$, make it much more attractive to potential employees to work officially and escape engagement in underground activities.

Fourth, our results suggest that an increase in the size of the informal sector may come out of policies aimed to make unemployment compensation more generous. This finding is similar to Boeri's (1999) observation that overly generous non-employment benefits at the outset of transition in some countries of Eastern Europe favoured a drive to non-employment, which in his model in effect implies employment in the informal sector. The crucial difference between his and our work is that in Boeri's model an increase in wages as a repercussion of higher unemployment benefits does not affect the decision of employers to take off in the informal economy: it is only the non-employed, who prefer draw benefits and on the top of that, enjoy informal activities. By contrast, in our model, an increase in benefits affects relative sizes of surpluses in each sector, and thus also has a direct effect on the proportion of employers posting vacancies in the informal market.

Fifth, Table 1 suggests that better monitoring and higher fines for working informally are, perhaps, the most straightforward way to shackle the informal economy, while additional labour market regulations such as redundancy pay in the formal firms should not be of great concern for policy makers taking stock of the size and extents of the shadow sector.

Finally, it is easy to notice that all the policy measures cutting down the size of the informal sector at the same time reduce unemployment. Thus, this model makes out a case for arguing that not only policies aimed at reducing unemployment pay off by scaling down the shadow sector (Boeri and Garibaldi, 2001), but also direct policies aimed at reducing the size of the latter (such as an increase in monitoring intensity, $m$, or fines, $F$ ) bring about a higher level of employment in the economy. This finding contradicts a conclusion of Boeri and Garibaldi (2001), who say that any attempts to reduce shadow employment will result in higher unemployment. We explain this by the fact that any increase in the proportion of formal vacancies accompanied by an increase in the number of filled formal jobs results in a greater number of workers staying employed (as duration of jobs in the formal sector is higher), while unemployment becomes less significant.

Having known the effects of changes in parameters one might raise a question about purposefulness of conducting policies aimed at reducing the share of the informal sector in the economy. In general, it is possible to think of a number of reasons why governments may be interested in increasing the number of official firms. Shleifer and Vishny (1998), for example, suggest that such reasons may emanate from properly organised fiscal systems, politicians' desire to win greater support for elections, direct financial interests of politicians (shareholding). On the other hand, a benevolent government interested in raising economic welfare would strive to scale down the informal economy if a greater shadow sector reduces welfare of economic agents.

In the discussion above we did not touch welfare implications, namely, which of the equilibrium outcomes is more socially optimal. Now we move on to reflect 
on efficiency issues of the mixed equilibrium and consider possible restrictions on certain policies.

\section{Implications for Welfare}

\subsection{Total Surplus}

In analysing the welfare properties of equilibrium, we will follow Acemoglu (2001) and Hosios (1990), and consider the total steady-state surplus of the economy. We define it as total surplus in both sectors minus costs. This measure is similar to net output of the economy, i.e. what Acemoglu (2001) calls the measure that an agent would care before entering the economy. However, in our case it is not precisely the net output as the surplus in the formal sector includes non-wage benefits $b_{f}$, which are received by formal workers but do not result from productivity of a match.

Let us write down the total surplus in steady state as

$$
\Xi(\theta, \phi)=N S_{f}+I S_{i}-\theta U\left(\phi \pi k_{f}+(1-\phi) \rho k_{i}\right)+U b_{u}
$$

This surplus is equal to total flow surplus in both sectors, which consists of the number of workers in formal jobs, $N=(1-U) \phi \frac{\delta+m}{\delta+m \phi}$, times the formal sector surplus, $S_{f}=y+b_{f}-\tau-k_{f} \pi$, plus the number of workers in informal jobs, $I=(1-U)(1-\phi) \frac{\delta}{\delta+m \phi}$, times the informal surplus, $S_{i}=y-m F-k_{i} \rho$, minus the flow costs of job creation for formal and informal vacancies (respectively, $\theta U \phi \pi k_{f}$ and $\left.\theta U(1-\phi) \rho k_{i}\right)$, plus total flow benefits received by the unemployed, $U b_{u} \cdot{ }^{21}$ Notice that the proportion of formal vacancies among all vacancies, $\phi$, and proportion of filled formal jobs among all filled jobs, $\phi \frac{\delta+m}{\delta+m \phi}$, do not coincide due to different job duration rates in different sectors. Also, it can be shown that $U=\frac{\delta(m+\delta)}{\delta(m+\delta)+\alpha(\theta)(m \phi+\delta)}$ (see Appendix A for derivation of these results), the stock of unemployed workers in steady state, is in fact a function of $\theta$ and $\phi$.

Suppose now that there is another agent in our economy, namely a benevolent government. ${ }^{22}$ Such a government would, for example, be committed to maximising (23) subject to the net tax revenue constraint:

$$
\tau N+m F I-b_{u} U-b_{f} N=\Omega
$$

The equation (24) reads that the net tax revenue consists of taxes collected from formal jobs, $\tau N$, plus fines collected from informal jobs, $m F I$, less unemployment benefits paid to the jobless, $b_{u} U$, less non-wage benefits provided in the formal sector, $b_{f} N$. This net tax revenue has to equal some value $\Omega$.

\footnotetext{
${ }^{21}$ See footnote 3 in Hosios (1990) for the derivation of this formula for analysing the constrained Pareto efficiency in search models.

22 Notice, however, we still implicitly assume that at a lower level government officials are corrupt, and prompt higher costs of opening a formal vacancy, $k_{f}$.
} 
Allocations of jobs delivering maximum to (23) subject to (24) and constraints on $U(\theta, \phi)$ are (constrained) Pareto efficient. In general, the problem of Pareto ranking equilibria shown in Fig.3-6 seems to be insoluble without further assumptions about parameters of the model. It is likely that the same value of the total surplus may be achieved in different equilibria depending on the resulting equilibrium value of the market tightness. However, we can try to answer the question about what the government should do, given that it starts in a situation when the economy is already in region D, Fig.2 (i.e. when both formal and informal economies are stably present), and what would be an efficient outcome for such a government.

\subsection{Inefficiency of Mixed Equilibrium}

By substituting (24) into (23) the government problem is reduced to maximisation of

$$
\Xi_{r}(\theta, \phi)=N\left(y-\pi k_{f}\right)+I\left(y-\rho k_{i}\right)-\theta U\left(\phi \pi k_{f}+(1-\phi) \rho k_{i}\right)-\Omega .
$$

In mixed equilibrium $\pi k_{f}<\rho k_{i}$, by assumption, so an increase in the number of filled formal jobs, $N$, accompanied by an equivalent or smaller decrease in the number of informal jobs, $I$, would increase the value of (25). Also, if in addition, the proportion of formal vacancies, $\phi$, increases, while the value of the market tightness, $\theta$, decreases, the value of (25) rises even more, as it leads to a decrease in the value of the third term in the sum above (see Appendix A for proof).

Proposition 4 If the government starts in region D in Fig.2, in order to raise the level of welfare in the economy it should conduct such policies as to increase the number of formal jobs, $N$, not as much decrease the number of informal jobs, $I$, raise the proportion of formal vacancies, $\phi$, and reduce the market tightness, $\theta$, provided that the net tax revenue amounts to $\Omega$.

Thus, any policy producing such a result would move the economy to a more efficient position.

Proposition 5 Each of the policies considered in Table 1 and resulting in a reduction in size of the informal sector increase the value of the total surplus.

The formal proofs of these results are given in Appendix A. Here we just note that if the equilibrium allocation of jobs across sectors is efficient, partial derivatives of (25) with respect to parameters of the model must be equal to zero when evaluated in the interior equilibrium shown in Fig.5. However, given $\pi k_{f}<\rho k_{i}$ it is always the case that $\frac{\partial \Xi_{r}}{\partial b_{u}}<0, \frac{\partial \Xi_{r}}{\partial b_{f}}>0, \frac{\partial \Xi_{r}}{\partial m}>0, \frac{\partial \Xi_{r}}{\partial F}>0$, $\frac{\partial \Xi_{r}}{\partial \tau}<0, \frac{\partial \Xi_{r}}{\partial \beta}<0$, and $\frac{\partial \Xi_{r}}{\partial k_{f}}<0$, whenever parameters of the model satisfy conditions for the mixed equilibrium, in particular, $\tau-b_{f}>m F$. Thus by raising $m, F, b_{f}$, and/or decreasing $\tau, k_{f}$ and $b_{u}$ the value of reduced total surplus can always be increased. 
Corollary 6 The mixed equilibrium is not efficient: the government always has a possibility to improve on welfare in the economy by choosing among policy measures suggested in Table 1.

Starting off at the mixed equilibrium (Fig.6) the government can lead the economy to end up either in no shadow equilibrium (Fig.5) or shadow sector equilibrium (Fig.4). In the former case, the total welfare will increase, in the latter case it will decrease. This suggests another corollary.

Corollary 7 Given $\pi k_{f}<\rho k_{i}$, the most efficient result for the economy would be an equilibrium with formal jobs only.

\subsection{Further Notes on Policies}

Although, policies for improving on efficiency are galore, not all of them can be carried out together at the same time. For example, an increase in the formal sector benefits, $b_{f}$, raising economic welfare, would likely require an increase in taxes, $\tau$, leading to a decrease in welfare. This can happen because we assumed a constraint on the net tax revenue. But even in the case when an increase in welfare is, in principle, feasible - for example, the government can simultaneously reduce taxes and unemployment benefits so that the net tax revenue is still equal to $\Omega$, - other constraints may limit the degree to which welfare can be raised. So, there can exist some subsistence level $\underline{b}$, below which unemployment benefits, $b_{u}$, just cannot be brought. Thus the problem of the government looks very challenging indeed, while our model anyway suggests simple policy tools and avenues to explore for policymakers.

First, as we have just noted, unemployment benefits may play an important role in raising economic welfare. It has already been shown by Acemoglu and Shimer (1999a) in a search set-up with risk averse workers that unemployment benefits may improve distribution of resources and restore the economy to the output maximising allocation. Other studies by Diamond (1981), Marimon and Zilibotti (1999) and Acemoglu (2001) have also pointed out an efficiency increasing role of unemployment insurance in search models with risk neutrality. In our model, however, it is the less generous unemployment insurance that has a positive effect on total welfare. Providing more lavish unemployment compensation just gets the jobless more interested in informal jobs with higher pay. Hence, it leads to an increase in the number of informal matches, which has a negative effect on total welfare.

Second, increasing monitoring of informal jobs and fines for running shadow businesses probably represents the most direct way to cut down the size of the informal sector and increase welfare. However, in reality it could well not be easy to fulfill because of a number of reasons left out by our model. To start with, an increase in monitoring intensity is likely to imply better financing of corresponding authorities, i.e. it prompts additional governmental expenses. Thus, again, governments may be constrained by their budgets, and an intensified audit is likely to require heavier taxation. Instead, governments may wish 
to opt more decidedly for an increase in fines to do away with the informal sector. However, an increase in fines' size must be credible, i.e. such fines must be credibly levied and collected to take effect. In practice, however, tax and monitoring authorities may be corrupt and trade higher official fines for bribes, smaller in size, which go directly to tax inspectors, but not to the state (Safavian et al., 2001). Chander and Wilde (1992), for example, point out that if auditors accept bribes it is possible for increases in the fine rate or the tax rate to reduce expected government revenue. So, the size of levied fines can also be constrained in reality.

The suggestion pointing to the possibility of corruption among government officials (in addition to that generating higher entry barriers in the formal sector, considered in our model) reminds one that in practice governments often happen to be of a "grabbing hand" type in terminology of Shleifer and Vishny (1998), rather than of a "helping hand" type. The former will pursue purposes very different from those of maximising total welfare, which is an alleged objective of the latter type. Such a corrupt government, both likely to come across in despotic and democratic states, may well be interested, for example, in creating conditions for rent-seeking and bribery to flourish. In such a case, politicians would, for example, aim to increase possibilities for bribe-taking. In terms of parameters of our model, this implies that such a government would not only seek to maximise income originating from formal employers' having to pay high entrance costs $k_{f}$, but it may well also avoid shackling the informal sector by intense monitoring and large fines, as the mere existence of informal employers creates richer opportunities for bribe taking whenever informal producers get caught and face the real possibility of being closed. ${ }^{23}$

The natural implication of the analysis by Shleifer and Vishny (1998) is that the less the government of a grabbing hand type the better off the economy in terms of welfare. Within the limits of our model, the welfare unambiguously improves as $k_{f}$ lowers. That is, putting it differently, whenever the government seeks ways to combat corruption and bribery preventing entrepreneurs easy access to the formal sector the better off the economy.

To sum up, we have shown that policies aimed at reducing the share of the informal sector in the economy, are welfare improving in the case of a mixed equilibrium (Fig.6), which is, thus, inefficient. However, in practice governments are limited by various constraints and often resort to a mixture of policies. The overall welfare effect is difficult to predict, in this case. Nevertheless, we suggest that governments concentrating on anti-corruption measures and avoiding overburdening formal employers with taxes are likely to bring workers and entrepreneurs in the formal sector and improve their welfare.

\footnotetext{
${ }^{23}$ De Soto (1989) notes that many permits, licenses and regulations exist ptobably to give officials the power to deny them and to collect bribes in return for providing the permits. By the same token, the grabbing hand government will not try to weed out the shadow sector completely as detection of informal employers creates new opportunities for bribe-taking.
} 


\section{Concluding Remarks}

In this study we developed a model of search in the labour market in the presence of the informal sector when productivity of formal and informal parts of the economy is the same, but there are higher barriers to entry into the formal sector. This model better describes a situation in some Eastern European economies, especially countries-successors of the former Soviet Union republics. However, one can easily draw parallels to search models built for OECD countries (e.g. Boeri and Garibaldi, 2001; Fugazza and Jacques, 2002).

It was shown that under different values of parameters different equilibria can result from interaction of employers and jobseekers. In only one case the outcome is a stable equilibrium where the formal sector co-exists with the informal one. That equilibrium is characterised by sufficiently high taxes compared to low formal sector benefits and monitoring intensity of the informal sector. The effect of the latter on the potential irregular producers, however, is still significant enough at the entry stage to outweigh the effect of additional entry costs paid in the formal sector due to corruption. In section 3.2 we prove that such an equilibrium is not efficient and the governments should look for ways to weed out the informal sector and increase the number of formal jobs in the economy in order to improve total welfare.

The model supports the widely held opinion, following from both theoretical and empirical literature (inter alia Loayaza, 1996; Fortin et al., 1997; Johnson et al., 1997; Agénor and Aizenman,1999; Sarte, 2000; Fugazza and Jacques, 2002; etc.), that higher taxes, corruption, bribery lead potential employers into the irregular economy. In addition, we show that higher unemployment benefits also push off workers into informal jobs and negatively affect total surplus. We stress the importance of the formal sector non-wage benefits in reducing the scope of the shadow economy and raising welfare. This parallels to the result of Fugazza and Jacques (2002), who point out that individual benefits of participating in the regular sector are more desirable than a deterrence policy to cope with the informal economy. Perhaps, a surprising finding is that such formal regulation as redundancy pay does not affect the allocation of jobs in the economy as its effect is totally absorbed by wages in different sectors.

In general we support the idea of Boeri and Garibaldi (2001) that policies reducing unemployment result in the reduction of the informal sector. However, contrary to their belief it was shown that in the type of equilibrium we considered the opposite can be true as well: scaling down the informal sector can lead to a decrease in the level of unemployment.

All in all, this study suggests another view on the emergence of the irregular sector and supports Fugazza's and Jacques's (2002) argument that informality is an outcome of non-trivial interactions between various kinds of institutions (fiscal, labour market, etc.). Only through a thorough understanding of all these interactions a government can choose an effective way leading to welfare improvements. Reduction in the size of the informal sector is a general suggestion in the situation we focused on. 


\section{William Davidson Institute Working Paper 524}

\section{References}

[1] Acemoglu D. (1995) Reward Structures and the Allocation of Talent. European Economic Review. Vol. 39, pp.17-33.

[2] Acemoglu D. (2001) Good Jobs versus Bad Jobs. Journal of Labor Economics. Vol. 19, no.1, pp.1-21.

[3] Acemoglu D., Shimer R. (1999a) Efficient Unemployment Insurance. Journal of Political Economy. Vol. 107, October, pp.893-928.

[4] Acemoglu D., Shimer R. (1999b) Holdups and Efficiency with Search Frictions. International Economic Review, Vol. 40, No.4, November.

[5] Acemoglu D., Shimer R. (2000) Wages and Technology Dispersion. Review of Economic Studies, Vol.67, No.4, October.

[6] Acemoglu D., Verdier T. (1998) Property Rights, Corruption and the Allocation of Talent: A General Equilibrium Approach, Economic Journal, 108(450), pp.1381-1403.

[7] Agénor P.-R., Aizenman J. (1999) Macroeconomic Adjustment with Segmented Labor Markets. Journal of Development Economics. Vol. 58, pp.277-296.

[8] Becker G. (1965) A Theory of the Allocation of Time. Economic Journal, Vol. 75(299), September, pp.493-517.

[9] Becker G. (1968) Crime and Punishment: An Economic Approach. Journal of Political Economy, Vol. 76(2), March - April, pp.169-217.

[10] Boeri T., Garibaldi P. (2001) Shadow Activity and Unemployment in a Depressed Labor Market. IGIER Working Paper no. 77, Bocconi University, IGIER, Milano, Italy. 13 June.

[11] Chander P., Wilde L. (1992) Corruption in tax administration. Journal of Public Economics, Vol. 49(3), December, pp.333-349.

[12] De Soto H. (1989) The Other Path: the Invisible Revolution in the Third World. Harper and Row.

[13] Diamond P. (1981) Mobility Costs, Frictional Unemployment and Efficiency. Journal of Political Economy, Vol.89, August, pp.798-812.

[14] Fiorentini G., Peltzman S. eds. (1995) The Economics of Organised Crime. Cambridge University Press. 301p.

[15] Fortin B., Marceau N., Savard L. (1997) Taxation, Wage Controls and the Informal Sector. Journal of Public Economics, Vol. 66(2), November, pp.293-312. 
[16] Friedman E., Johnson S., Kaufmann D., Zoido-Lobaton P. (2000) Dodging the Grabbing Hand: the Determinants of Unofficial Activity in 69 Countries. Journal of Public Economics, Vol. 76, pp.459-493.

[17] Frye T., Zhuravskaya E. (1999) Rackets, Regulation and the Rule of Law. CEFIR Working Paper. CEFIR, Moscow, Russia.

[18] Fugazza M., Jacques J.-F. (2002) Labor Market Institutions, Taxation and the Underground Economy. Journal of Public Economics. In press.

[19] Gronau R. (1977) Leisure, Home Production, and Work - the Theory of the Allocation of Time Revisited. Journal of Political Economy, Vol.85(6), December, pp.1099-1124.

[20] Johnson S., Kaufmann D., McMillan J., Woodruff C. (2000) Why do Firms Hide? Bribes and Unofficial Activity after Communism. Journal of Public Economics, Vol. 76, Issue 3, June, pp.495-520.

[21] Kaufmann D. (1997) Why is Ukraine's Economy - and Russia's - not Growing? Transition. The World Bank. April.

[22] Kolev A. (1998) Labour Supply in the Informal Economy in Russia during Transition. Paper presented at the CEPR First Annual Transition Economics Summer Workshop. Prague. June-July.

[23] Lackó M. (2000) Hidden Economy - an Unknown Quantity? Comparative Analysis of Hidden Economies in Transition Countries, 1989-1995. Economics of Transition, Vol. 8(1), pp.117-149.

[24] Lemieux T., Fortin B., Frechette P. (1994) The Effects of Taxes on Labour Supply in the Underground Economy. American Economic Review, Vol.84(1), March, pp.231-254.

[25] Loayaza N. (1996) The Economics of the Informal Sector: A Simple Model and Some Empirical Evidence from Latin America. Carnegie-Rochester Conference Series on Public Policy, Vol. 45, pp.129-162.

[26] Marimon R., Zilibotti F. (1999) Unemployment vs Mismatch of Talent. Economic Journal, April, pp.266-291.

[27] Murphy K.M., Shleifer A., Vishny R.W. (1993) Why is Rent-Seeking So Costly to Growth? American Economic Review Papers and Proceedings, Vol. 83, no. 2, May, pp.409-414.

[28] Nash J. (1950) The Bargaining Problem. Econometrica, Vol. 18, no. 2, April, pp.155-162.

[29] Pissarides C. (2000) Equilibrium Unemployment Theory. 2nd edition, Cambridge, MA, London, UK, MIT press. 


\section{William Davidson Institute Working Paper 524}

[30] Safavian M, Graham D., Gonzalez-Vega C. (2001) Corruption and Microenterprises in Russia. World Development Vol. 29, no. 7, pp.1215-1224.

[31] Sarte P-D.G. (2000) Informality and Rent-seeking Bureaucracies in a Model of Long-run Growth. Journal of Monetary Economics, Vol.46, pp.173-197.

[32] Schneider F. (2000) The Value Added of Underground Activities: Size and Measurement of the Shadow Economies and Shadow Economy Labor Force All Over the World. Johannes Kepler University of Linz, Austria. July.

[33] Schneider F. (2001) The Size and Development of the Shadow Economies and Shadow Economy Labor Force of 18 Asian and 21 OECD Countries: First Results for the 90s. Invited paper prepared for the Asia Pacific Finance Association (APFA) Conference 2001 "Rebuilding Our Financial Architecture" held in Bangkok, Thailand, July 22-25, 2001.April.

[34] Schneider F., Enste D.H. (2000) Shadow Economies: Size, Causes, and Consequences. Journal of Economic Literature, Vol. 38, no. 1, pp.77-114

[35] Shleifer A., Vishny R.W. (1998) The Grabbing Hand. Government Pathologies and Their Cures. Harvard University Press, Cambridge, MA, London, England. 278p.

[36] Thomas J.J. (1992) Informal Economic Activity. LSE Handbooks in Economics. London.

[37] Vostroknoutova E. (2002) Institutional Lock-in during Transition: Why do Informal Activities Matter? Paper presented at the VIIth Spring Meeting of Young Economists, Université Paris I, Panthéon-Sorbonne, Paris, April 18-20. 


\section{A Proofs}

Proposition 1. There exists some threshold value of the market tightness $\bar{\theta}$, defined by the parameters $k_{f}, k_{i}, \beta, r, \delta, b_{f}, b_{u}, \tau, m, F$, and parameters of the matching function, such that for parameter values satisfying conditions in region 2, Fig.1, and for any $\theta>\bar{\theta}$ the derivative $\frac{\partial E_{u}(\theta, \phi)}{\partial \phi}$ is negative, and for any $\theta<\bar{\theta}$ it is positive.

Proof:

By definition $E_{u}(\theta, \phi, \cdot)=\frac{b_{u} \pi \rho+\alpha(\theta) \beta\left(\phi \rho S_{f}+(1-\phi) \pi S_{i}\right)}{r(\alpha(\theta) \beta((1-\phi) \pi+\phi \rho)+\pi \rho)}$.

$\frac{\partial E_{u}(\theta, \phi, \cdot)}{\partial \theta}=\frac{\partial \alpha(\theta)}{\partial \theta} \beta \pi \rho \frac{\phi \rho\left(y+b_{f}-\tau-k_{f} \pi-b_{u}\right)+(1-\phi) \pi\left(y-m F-k_{i} \rho-b_{u}\right)}{r(\alpha(\theta) \beta((1-\phi) \pi+\phi \rho)+\pi \rho)^{2}}>0$

as $y+b_{f}-\tau-k_{f} \pi-b_{u}>0$ and $y-m F-k_{i} \rho-b_{u}>0$ by assumption.

$\frac{\partial E_{u}(\theta, \phi, \cdot)}{\partial \phi}=$

$=\alpha(\theta) \beta \pi \rho \frac{\rho\left(y+b_{f}-\tau-k_{f} \pi-b_{u}\right)-\pi\left(y-m F-k_{i} \rho-b_{u}\right)+\alpha(\theta) \beta\left(b_{f}+m F-\tau-k_{f} \pi+k_{i} \rho\right)}{r(\alpha(\theta) \beta((1-\phi) \pi+\phi \rho)+\pi \rho)^{2}}=$

$=\alpha(\theta) \beta \pi \rho \frac{\rho\left(S_{f}-b_{u}\right)-\pi\left(S_{i}-b_{u}\right)+\alpha(\theta) \beta\left(S_{f}-S_{i}\right)}{r(\alpha(\theta) \beta((1-\phi) \pi+\phi \rho)+\pi \rho)^{2}}$

The restrictions on parameter values in region 2, Fig.1 imply $\frac{S_{f}-b_{u}}{S_{i}-b_{u}}<1$ and $\frac{\rho}{\pi}>\frac{S_{i}-b_{u}}{S_{f}-b_{u}}$.

Hence, $S_{f}-S_{i}<0$ and $\rho\left(S_{f}-b_{u}\right)-\pi\left(S_{i}-b_{u}\right)>0$.

Thus, $\frac{\partial E_{u}(\theta, \phi, \cdot)}{\partial \phi}>0$ if $\rho\left(S_{f}-b_{u}\right)-\pi\left(S_{i}-b_{u}\right)>-\alpha(\theta) \beta\left(S_{f}-S_{i}\right)$ and

$\frac{\partial E_{u}(\theta, \phi, \cdot)}{\partial \phi}<0$ if $\rho\left(S_{f}-b_{u}\right)-\pi\left(S_{i}-b_{u}\right)<-\alpha(\theta) \beta\left(S_{f}-S_{i}\right)$.

Or, alternatively, $\frac{\partial E_{u}(\theta, \phi, \cdot)}{\partial \phi}>0$ if $\alpha(\theta)<-\frac{\rho\left(S_{f}-b_{u}\right)-\pi\left(S_{i}-b_{u}\right)}{\beta\left(S_{f}-S_{i}\right)}$ and

$\frac{\partial E_{u}(\theta, \phi, \cdot)}{\partial \phi}<0$ if $\alpha(\theta)>-\frac{\rho\left(S_{f}-b_{u}\right)-\pi\left(S_{i}-b_{u}\right)}{\beta\left(S_{f}-S_{i}\right)}$.

Define $\bar{\theta}$ as $\bar{\theta}=\alpha^{-1}\left(-\frac{\rho\left(S_{f}-b_{u}\right)-\pi\left(S_{i}-b_{u}\right)}{\beta\left(S_{f}-S_{i}\right)}\right)$, then by properties of function $\alpha(\theta)$ we have

$\frac{\partial E_{u}(\theta, \phi, \cdot)}{\partial \phi}>0$ if $\theta<\bar{\theta}$ and $\frac{\partial E_{u}(\theta, \phi, \cdot)}{\partial \phi}<0$ if $\theta>\bar{\theta}$.

Q.E.D.

Proposition 3. Let $\bar{\theta}$ be a threshold value of market tightness such that $\frac{\partial E_{u}(\bar{\theta}, \phi)}{\partial \phi}=0$ and $\left(\theta^{*}, \phi^{*}\right)$ be a point of an interior equilibrium in region D, Fig.2. Then $\theta^{*}$ is always less than $\bar{\theta}$.

Proof:

From Proposition 1 it follows that $\alpha(\bar{\theta})=-\frac{\rho\left(S_{f}-b_{u}\right)-\pi\left(S_{i}-b_{u}\right)}{\beta\left(S_{f}-S_{i}\right)}>0$.

At the point of an interior equilibrium both zero profit conditions hold, i.e. $q\left(\theta^{*}\right) \frac{(1-\beta)\left(y+b_{f}-\tau-r E_{u}\left(\theta^{*}, \phi^{*}, \cdot\right)\right)}{\pi\left(r+q\left(\theta^{*}\right)(1-\beta)\right.}=k_{f}$, and

$q\left(\theta^{*}\right) \frac{(1-\beta)\left(y-m F-r E_{u}\left(\theta^{*}, \phi^{*}, \cdot\right)\right)}{\rho\left(r+q\left(\theta^{*}\right)(1-\beta)\right)}=k_{i}$,

or

$q\left(\theta^{*}\right)=\frac{k_{f} r \pi}{(1-\beta)\left(y+b_{f}-\tau-k_{f} \pi-r E_{u}\left(\theta^{*}, \phi^{*}, \cdot\right)\right)}$, and

$q\left(\theta^{*}\right)=\frac{k_{i} r \rho}{(1-\beta)\left(y-m F-k_{i} \rho-r E_{u}\left(\theta^{*}, \phi^{*}, \cdot\right)\right)}$.

Then equating the two ratios we get

$\frac{k_{f} r \pi}{\left(y+b_{f}-\tau-k_{f} \pi-r E_{u}\left(\theta^{*}, \phi^{*}, \cdot\right)\right)}=\frac{k_{i} r \rho}{\left.\left(y-m F-k_{i} \rho-r E_{u}\left(\theta^{*}, \phi^{*}, \cdot\right)\right)\right)}$ or

$E_{u}\left(\theta^{*}, \phi^{*}, \cdot\right)=\frac{k_{f} \pi(y-m F)-k_{i} \rho\left(y+b_{f}-\tau\right)}{r\left(k_{f} \pi-k_{i} \rho\right)}=\frac{k_{f} \pi(y-m F)-k_{i} \rho\left(y+b_{f}-\tau\right)}{r\left(k_{f} \pi-k_{i} \rho\right)}$ 
Substituting the expression for $E_{u}\left(\theta^{*}, \phi^{*}, \cdot\right)$ we get

$\frac{b_{u} \pi \rho+\alpha\left(\theta^{*}\right) \beta\left(\phi^{*} \rho S_{f}+\left(1-\phi^{*}\right) \pi S_{i}\right)}{r\left(\alpha\left(\theta^{*}\right) \beta\left(\left(1-\phi^{*}\right) \pi+\phi^{*} \rho\right)+\pi \rho\right)}=\frac{k_{f} \pi(y-m F)-k_{i} \rho\left(y+b_{f}-\tau\right)}{r\left(k_{f} \pi-k_{i} \rho\right)}$.

Solving it for $\alpha\left(\theta^{*}\right)$ yields

$\alpha\left(\theta^{*}\right)=\frac{k_{i} \rho\left(S_{f}-b_{u}\right)-k_{f} \pi\left(S_{i}-b_{u}\right)}{\beta\left(S_{i}-S_{f}\right)\left(k_{f} \phi^{*}+k_{i}\left(1-\phi^{*}\right)\right)}>0$.

Now we can compare $\alpha\left(\theta^{*}\right)$ and $\alpha(\bar{\theta})$.

So, we have:

$\alpha(\bar{\theta})=\frac{\rho\left(S_{f}-b_{u}\right)-\pi\left(S_{i}-b_{u}\right)}{\beta\left(S_{i}-S_{f}\right)}$ and $\alpha\left(\theta^{*}\right)=\frac{k_{i} \rho\left(S_{f}-b_{u}\right)-k_{f} \pi\left(S_{i}-b_{u}\right)}{\beta\left(S_{i}-S_{f}\right)\left(k_{f} \phi^{*}+k_{i}\left(1-\phi^{*}\right)\right)}=>$

$\alpha(\bar{\theta})>\alpha\left(\theta^{*}\right)$ as $k_{f}>k_{i}$ and $\rho>\pi$ by assumption, which implies $\bar{\theta}>\theta^{*}$ given properties of $\alpha(\cdot)$.

Q.E.D.

Proposition 4. If the government starts in region D in Fig.2, in order to raise the level of welfare in the economy it should conduct such policies as to increase the number of formal jobs, $N$, not as much decrease the number of informal jobs, $I$, raise the proportion of formal vacancies, $\phi$, and reduce the market tightness, $\theta$, provided that the net tax revenue amounts to $\Omega$.

Proof:

Consider the function

$\Xi(\theta, \phi, \cdot)=N\left(y-k_{f} \pi\right)+I\left(y-k_{i} \rho\right)-\theta U\left(\phi \pi k_{f}+(1-\phi) \rho k_{i}\right)-\Omega$

1) In region D, Fig.2, we have $k_{f} \pi<k_{i} \rho$, so $\left(y-k_{f} \pi\right)>\left(y-k_{i} \rho\right)$. Thus, whenever $N$ rises, while $I$ proportionally decreases $\Xi(\theta, \phi, \cdot)$ rises as well.

2) Now, let $U$ be $U=\frac{\delta(m+\delta)}{\delta(m+\delta)+\alpha(\theta)(m \phi+\delta)}$ (see below derivation of this formula).

For the function

$\theta U(\theta, \phi, \cdot)=\frac{\theta \delta(\delta+m)}{\delta(\delta+m)+\alpha(\theta)(\delta+m \phi)}=\frac{\delta}{\frac{\delta}{\theta}+\frac{\alpha(\theta)}{\theta} \frac{(\delta+m \phi)}{(\delta+m)}}=\frac{\delta}{\frac{\delta}{\theta}+q(\theta) \frac{(\delta+m \phi)}{(\delta+m)}}$

we have

$\frac{\partial}{\partial \theta}(\theta U(\theta, \phi, \cdot))=\frac{\partial}{\partial \theta}\left(\frac{\delta}{\frac{\delta}{\theta}+q(\theta) \frac{(\delta+m \phi)}{(\delta+m)}}\right)>0$

and

$\frac{\partial}{\partial \phi}(\theta U(\theta, \phi, \cdot))=\frac{\partial}{\partial \phi}\left(\frac{\delta}{\frac{\delta}{\theta}+q(\theta) \frac{(\delta+m \phi)}{(\delta+m)}}\right)<0$

Thus, whenever $\phi \uparrow$, while $\theta \downarrow$, the value of $\theta U(\theta, \phi, \cdot)$ decreases.

3) Finally, whenever $\phi \uparrow$ the sum $\left(\phi \pi k_{f}+(1-\phi) \rho k_{i}\right)$ decreases as $k_{f} \pi<$ $k_{i} \rho$.

All three results together prove the proposition.

Q.E.D.

Proposition 5. Each of the policies considered in Table 1 and resulting in a reduction in size of the informal sector increase the value of the total surplus.

Sketch of the proof:

We consider a case of an increase in non-wage benefits, $b_{f}$ (the cases of other parameters can be proved by analogy).

It is easy to verify that for such an increase we will have:

$\frac{d \theta^{*}}{d b_{f}}=\frac{q^{2}\left(\theta^{*}\right)(1-\beta)}{\frac{\partial q\left(\theta^{*}\right)}{\partial \theta} r\left(k_{i} \rho-k_{f} \pi\right)}<0$ and 
$\frac{d \phi^{*}}{d b_{f}}=\frac{k_{i} \rho\left(1-r \frac{\partial E\left(\theta^{*}, \phi^{*}, \cdot\right)}{\partial b_{f}}\right)+k_{f} \pi r \frac{\partial E\left(\theta^{*}, \phi^{*}, \cdot\right)}{\partial b_{f}}}{\left(k_{i} \rho-k_{f} \pi\right) r \frac{\partial E\left(\theta^{*}, \phi^{*}, \cdot\right)}{\partial \phi}}-\frac{q^{2}\left(\theta^{*}\right)(1-\beta) \frac{\partial E\left(\theta^{*}, \phi^{*}, \cdot\right)}{\partial \theta}}{\frac{\partial q(\theta *)}{\partial \theta} r\left(k_{i} \rho-k_{f} \pi\right) \frac{\partial E\left(\theta^{*}, \phi^{*}, \cdot\right)}{\partial \phi}}>0$, before.

where $\frac{\partial E\left(\theta^{*}, \phi^{*}, \cdot\right)}{\partial b_{f}}=\frac{\alpha\left(\theta^{*}\right) \beta \phi^{*} \rho}{r\left(\alpha\left(\theta^{*}\right) \beta\left(\left(1-\phi^{*}\right) \pi+\phi^{*} \rho\right)+\pi \rho\right)}>0$ and all other terms as

At the same time, the effects on stocks at the equilibrium point are given by $\frac{\partial N(\cdot)}{\partial b_{f}}=$

$=\frac{\delta(m+\delta)}{\left(\delta(m+\delta)+\alpha\left(\theta^{2}\right)(m \phi\right.}$

$=\frac{\delta(m+\delta)}{\left(\delta(m+\delta)+\alpha\left(\theta^{*}\right)\left(m \phi^{*}+\delta\right)\right)^{2}} *$

$*\left(\alpha\left(\theta^{*}\right)\left(m+\delta+\alpha\left(\theta^{*}\right)\right) \frac{\partial \phi^{*}}{\partial b_{f}}+\frac{\partial \alpha\left(\theta^{*}\right)}{\partial \theta} \frac{\partial \theta^{*}}{\partial b_{f}} \phi^{*}(m+\delta)\right)>0 ;$

$\frac{\partial I(\cdot)}{\partial b_{f}}=$

$=\frac{\delta(m+\delta)}{\left(\delta(m+\delta)+\alpha\left(\theta^{*}\right)\left(m \phi^{*}+\delta\right)\right)^{2}} *$

$*\left(-\alpha\left(\theta^{*}\right)\left(\delta+\alpha\left(\theta^{*}\right)\right) \frac{\partial \phi^{*}}{\partial b_{f}}+\frac{\partial \alpha\left(\theta^{*}\right)}{\partial \theta} \frac{\partial \theta^{*}}{\partial b_{f}}\left(1-\phi^{*}\right) \delta\right)<0 ;$

$\frac{\partial U(\cdot)}{\partial b_{f}}=$

$=-\frac{\delta(m+\delta)}{\left(\delta(m+\delta)+\alpha\left(\theta^{*}\right)\left(m \phi^{*}+\delta\right)\right)^{2}}\left(\alpha\left(\theta^{*}\right) m \frac{\partial \phi^{*}}{\partial b_{f}}+\frac{\partial \alpha\left(\theta^{*}\right)}{\partial \theta} \frac{\partial \theta^{*}}{\partial b_{f}}\left(m \phi^{*}+\delta\right)\right)<0 ;$

where

$N(\cdot)=\frac{\alpha(\theta) \phi(m+\delta)}{\delta(m+\delta)+\alpha(\theta)(m \phi+\delta)}$,

$I(\cdot)=\frac{\delta \alpha(\theta)(1-\phi)}{\delta(m+\delta)+\alpha(\theta)(m \phi+\delta)}$

$U(\cdot)=\frac{\delta(m+\delta)}{\delta(m+\delta)+\alpha(\theta)(m \phi+\delta)}$ (see below).

Now consider the derivative of the reduced total surplus with respect to $b_{f}$ at the equilibrium point:

$$
\begin{aligned}
& \frac{\partial \Xi_{r}}{\partial b_{f}}=\frac{\partial N}{\partial b_{f}}\left(y-k_{f} \pi\right)+\frac{\partial I}{\partial b_{f}}\left(y-k_{i} \rho\right)-\frac{\partial}{\partial b_{f}}\left(\theta U\left(\phi \pi k_{f}+(1-\phi) \rho k_{i}\right)\right)= \\
& =\frac{\partial N}{\partial b_{f}}\left(y-k_{f} \pi\right)+\frac{\partial I}{\partial b_{f}}\left(y-k_{i} \rho\right) \\
& -\left(\phi \pi k_{f}+(1-\phi) \rho k_{i}\right) \frac{\partial}{\partial b_{f}}(\theta U)-(\theta U) \frac{\partial}{\partial b_{f}}\left(\phi \pi k_{f}+(1-\phi) \rho k_{i}\right)= \\
& =\frac{\partial N}{\partial b_{f}}\left(y-k_{f} \pi\right)+\frac{\partial I}{\partial b_{f}}\left(y-k_{i} \rho\right) \\
& -\left(\phi \pi k_{f}+(1-\phi) \rho k_{i}\right)\left(\frac{\partial \theta}{\partial b_{f}} U+\frac{\partial U}{\partial b_{f}} \theta\right)-(\theta U) \frac{\partial \phi}{\partial b_{f}}\left(\pi k_{f}-\rho k_{i}\right)
\end{aligned}
$$

As we have $\frac{\partial N(\cdot)}{\partial b_{f}}>0$, while $\frac{\partial I(\cdot)}{\partial b_{f}}<0$ and $\frac{\partial U(\cdot)}{\partial b_{f}}<0$, this implies that $\left|\frac{\partial N(\cdot)}{\partial b_{f}}\right|>\left|\frac{\partial I(\cdot)}{\partial b_{f}}\right|$.

(By assumption $N+I+U=1$ - see below).

Then $\frac{\partial N}{\partial b_{f}}\left(y-k_{f} \pi\right)+\frac{\partial I}{\partial b_{f}}\left(y-k_{i} \rho\right)>0$. that

From above we have $\frac{\partial \theta}{\partial b_{f}}<0$ and $\frac{\partial U}{\partial b_{f}}<0$, while $\frac{d \phi^{*}}{d b_{f}}>0$ and $\pi k_{f}<\rho k_{i}$, so

$$
-\left(\phi \pi k_{f}+(1-\phi) \rho k_{i}\right)\left(\frac{\partial \theta}{\partial b_{f}} U+\frac{\partial U}{\partial b_{f}} \theta\right)-(\theta U) \frac{\partial \phi}{\partial b_{f}}\left(\pi k_{f}-\rho k_{i}\right)>0 .
$$

Thus, bringing pieces together, $\frac{\partial \Xi_{r}}{\partial b_{f}}$ is always positive at the equilibrium point. So by increasing $b_{f}$ we can increase both the proportion of formal vacancies, $\frac{d \phi^{*}}{d b_{f}}>0$, and the number of filled formal jobs, $\frac{\partial N}{\partial b_{f}}>0$, and the total surplus $\frac{\partial \Xi_{r}}{\partial b_{f}}>0$, provided that the constraint on the government budget is met.

\section{Q.E.D.}


Proofs of other results

I. Derivatives of the profit functions

$\left.\frac{\partial \Pi_{f}(\theta, \phi, \cdot)}{\partial \theta}\right|_{\Pi_{f}(\theta, \phi, \cdot)=0}<0$ and $\left.\frac{\partial \Pi_{i}(\theta, \phi, \cdot)}{\partial \theta}\right|_{\Pi_{i}(\theta, \phi, \cdot)=0}<0$

Proof:

Formal profits are: $\Pi_{f}(\theta, \phi, \cdot)=q(\theta) \frac{(1-\beta)\left(y+b_{f}-\tau-r E_{u}(\theta, \phi, \cdot)\right)}{(r+q(\theta)(1-\beta)) \pi}-k_{f}$

$\Pi_{f}(\theta, \phi, \cdot)=0$ is equivalent to $\left(y+b_{f}-\tau-r E_{u}(\theta, \phi, \cdot)\right)=\frac{k_{f} \pi(r+q(\theta)(1-\beta))}{q(\theta)(1-\beta)}$

Then for the first zero profit condition we have:

$\left.\frac{\partial \Pi_{f}(\theta, \phi, \cdot)}{\partial \theta}\right|_{\Pi_{f}(\theta, \phi, \cdot)=0}=$

$=\left.r(1-\beta) \frac{\frac{\partial q(\theta)}{\partial \theta}\left(y+b_{f}-\tau-r E_{u}(\theta, \phi, \cdot)\right)-q(\theta) \frac{\partial E_{u}(\theta, \phi, \cdot)}{\partial \theta}(r+q(\theta)(1-\beta))}{(r+q(\theta)(1-\beta))^{2} \pi}\right|_{\Pi_{f}(\theta, \phi, \cdot)=0}=$

$=\frac{\frac{\partial q(\theta)}{\partial \theta} r k_{f} \pi-\frac{\partial E_{u}(\theta, \phi, \cdot)}{\partial \theta} r q^{2}(\theta)(1-\beta)}{q(\theta)(r+q(\theta)(1-\beta)) \pi}$

So, given $\frac{\partial E_{u}(\theta, \phi, \cdot)}{\partial \theta}>0$ and $\frac{\partial q(\theta)}{\partial \theta}<0$ we have $\left.\frac{\partial \Pi_{f}(\theta, \phi, \cdot)}{\partial \theta}\right|_{\Pi_{f}(\theta, \phi, \cdot)=0}<0$.

Informal profits are: $\Pi_{i}(\theta, \phi, \cdot)=q(\theta) \frac{(1-\beta)\left(y-m F-r E_{u}(\theta, \phi, \cdot)\right)}{(r+q(\theta)(1-\beta)) \rho}-k_{i}$

The second zero profit condition is $\Pi_{i}(\theta, \phi, \cdot)=0$, which is equivalent to $\left(y-m F-r E_{u}(\theta, \phi, \cdot)\right)=\frac{k_{i} \rho(r+q(\theta)(1-\beta))}{q(\theta)(1-\beta)}$

$\left.\frac{\partial \Pi_{i}(\theta, \phi, \cdot)}{\partial \theta}\right|_{\Pi_{i}(\theta, \phi, \cdot)=0}=$

$=\left.r(1-\beta) \frac{\frac{\partial q(\theta)}{\partial \theta}\left(y-m F-r E_{u}(\theta, \phi, \cdot)\right)-q(\theta) \frac{\partial E_{u}(\theta, \phi, \cdot)}{\partial \theta}(r+q(\theta)(1-\beta))}{(r+q(\theta)(1-\beta))^{2} \rho}\right|_{\Pi_{i}(\theta, \phi, \cdot)=0}=$

$=\frac{\frac{\partial q(\theta)}{\partial \theta} r k_{i} \rho-\frac{\partial E_{u}(\theta, \phi, \cdot)}{\partial \theta} r q^{2}(\theta)(1-\beta)}{q(\theta)(r+q(\theta)(1-\beta)) \rho}$

So, again given $\frac{\partial E_{u}(\theta, \phi, \cdot)}{\partial \theta}>0$ and $\frac{\partial q(\theta)}{\partial \theta}<0$ we have $\left.\frac{\partial \Pi_{i}(\theta, \phi, \cdot)}{\partial \theta}\right|_{\Pi_{i}(\theta, \phi, \cdot)=0}<0$.

Q.E.D.

II. Derivation of expressions for stocks and proportions of filled jobs at steady states

From Bellman equations, stocks at steady state must satisfy:

$\delta N=\alpha(\theta) \phi U$

$(\delta+m) I=\alpha(\theta)(1-\phi) U$

$\alpha(\theta) U=\delta N+(\delta+m) I$

$I+N+U=1$

Solution of this system is:

$U=\frac{\delta(m+\delta)}{\delta(m+\delta)+\alpha(\theta)(m \phi+\delta)}, I=\frac{\delta \alpha(\theta)(1-\phi)}{\delta(m+\delta)+\alpha(\theta)(m \phi+\delta)}$, and $N=\frac{\alpha(\theta) \phi(\delta+m)}{\delta(m+\delta)+\alpha(\theta)(m \phi+\delta)}$. Thus, the proportion of formal jobs in total number of jobs is given by:

$\frac{N}{N+I}=\frac{\frac{\alpha(\theta) \phi U}{\delta}}{\frac{\alpha(\theta) \phi U}{\delta}+\frac{\alpha(\theta)(1-\phi) U}{(\delta+m)}}=\phi \frac{\delta+m}{\delta+\phi m}$;

and, analogously, the proportion of informal jobs in total number of vacancies is

$\frac{I}{N+I}=\frac{\frac{\alpha(\theta)(1-\phi) U}{(\delta+m)}}{\frac{\alpha(\theta) \phi U}{\delta}+\frac{\alpha(\theta)(1-\phi) U}{(\delta+m)}}=(1-\phi) \frac{\delta}{\delta+\phi m}$.

Q.E.D. 
B Figures

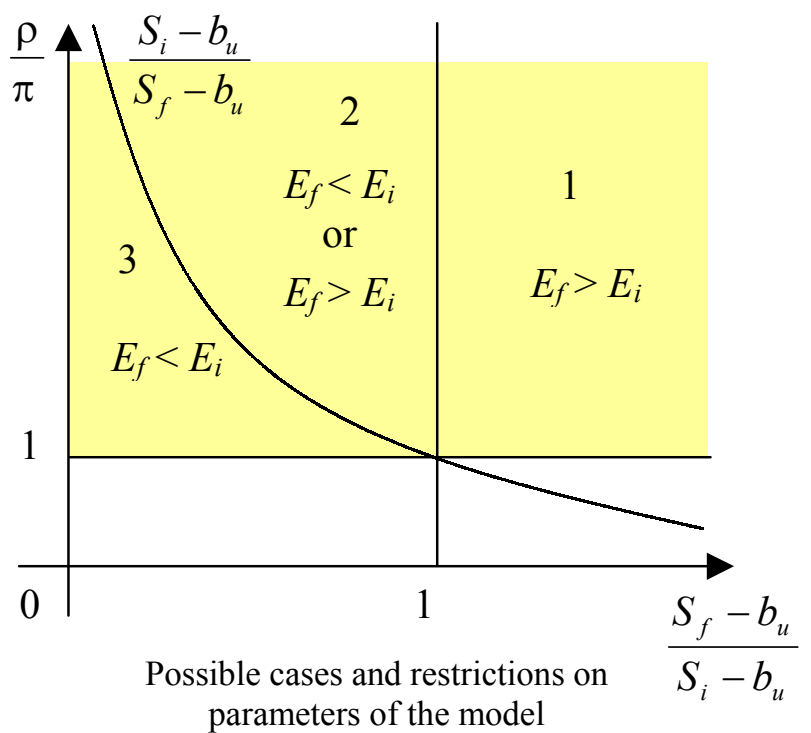

Fig.1

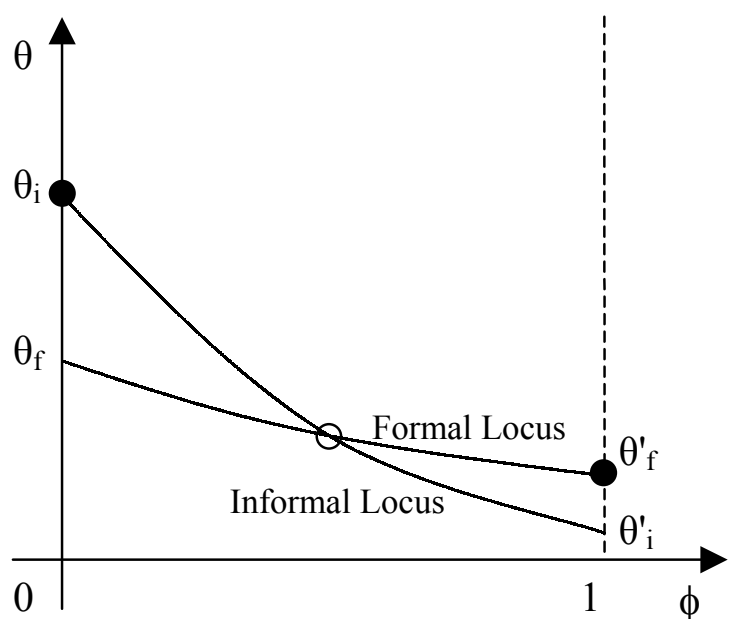

Multiple equilibria

Fig.3

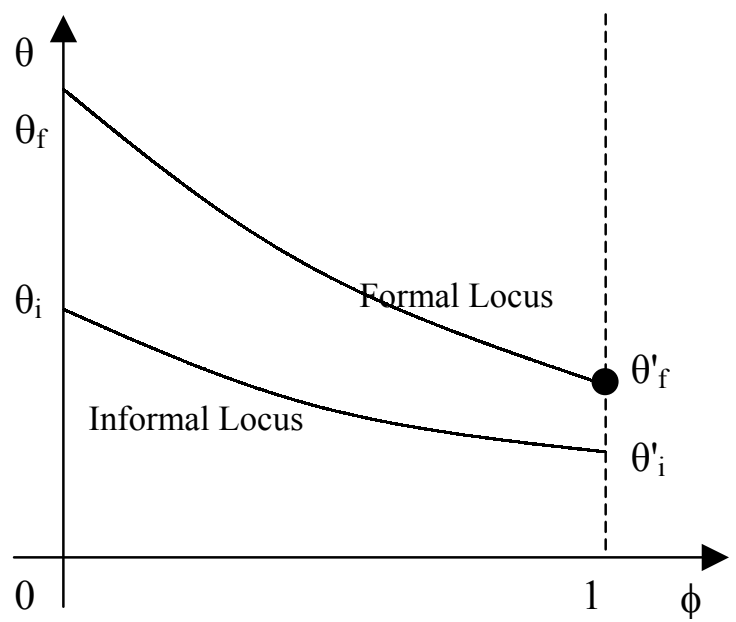

No shadow sector equilibrium

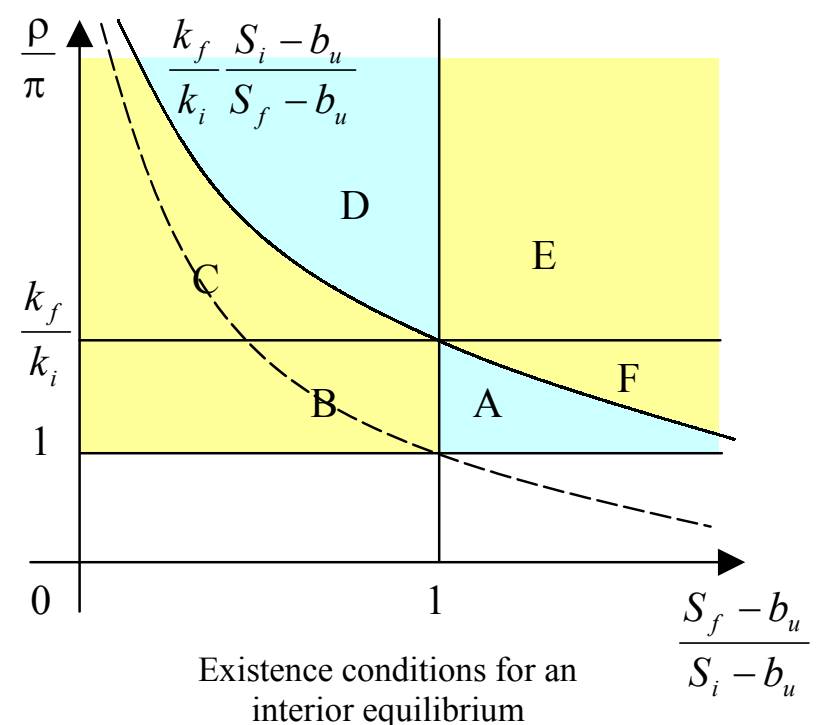

Fig.2

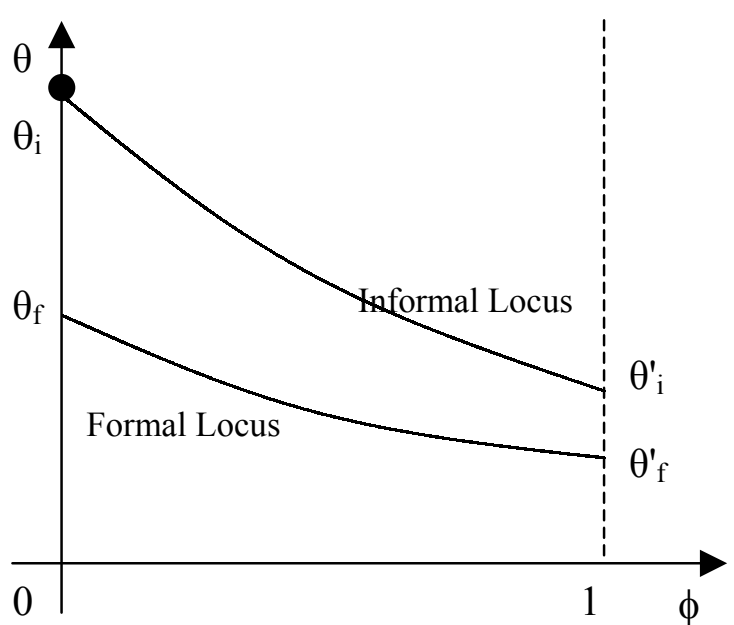

Shadow sector equilibrium

Fig.4

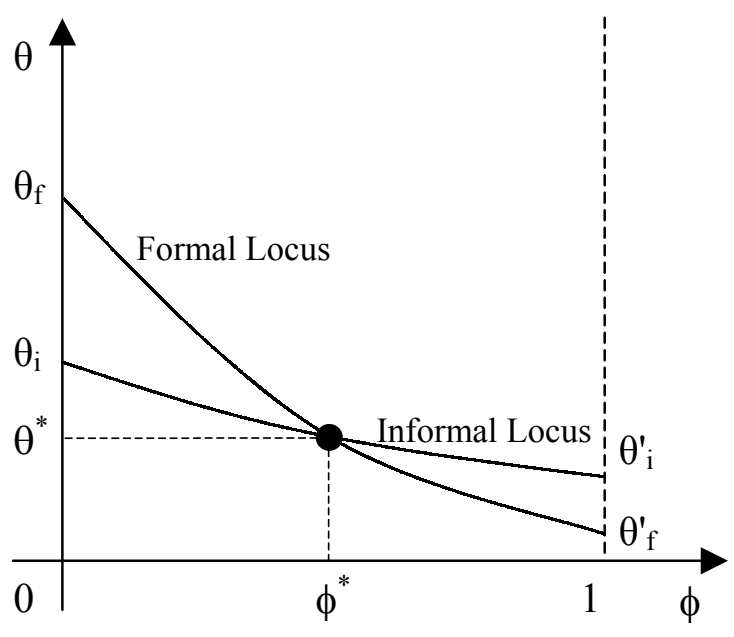

Stable interior equilibrium

Fig.6

Fig.5 


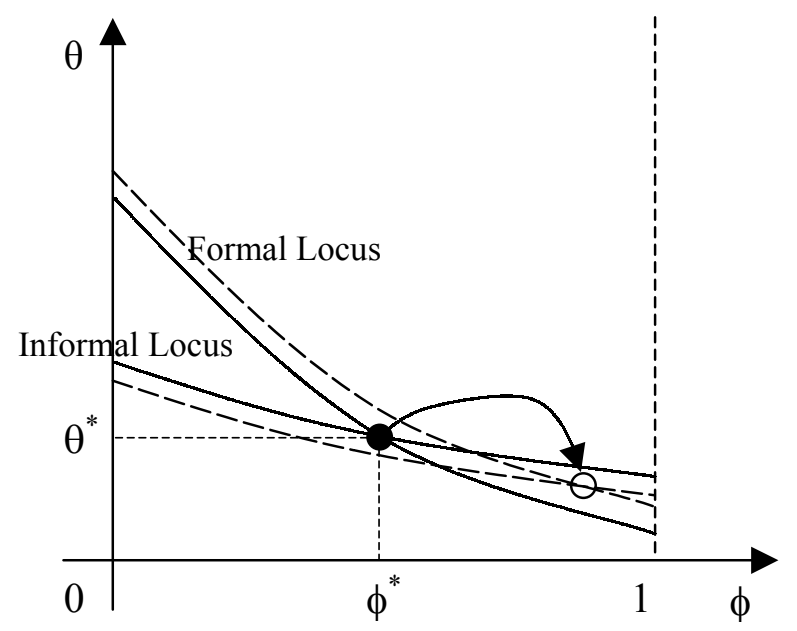

The effect of a rise in $m, F, b_{f}$, or a drop in $k_{f}$

Fig.7

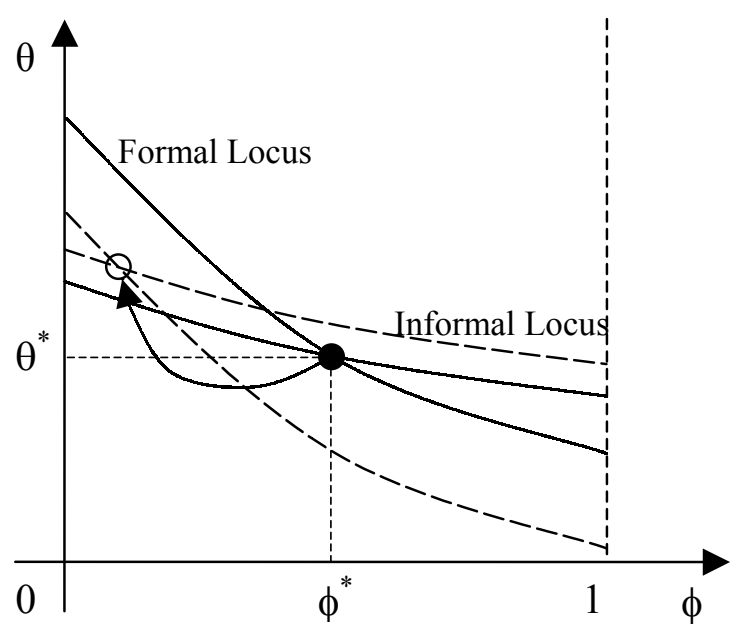

The effect of an increase in taxes

Fig. 8

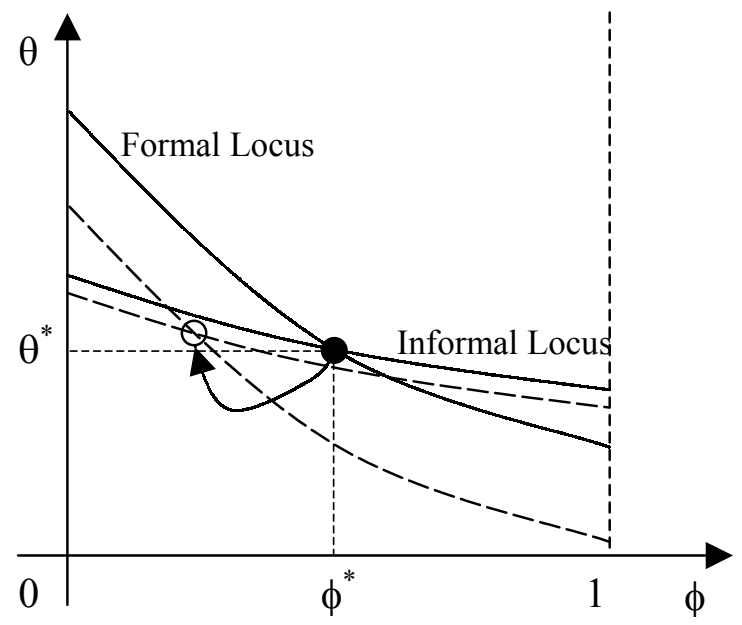

The effect of the minimum wage

Fig.9 


\section{DAVIDSON INSTITUTE WORKING PAPER SERIES - Most Recent Papers}

The entire Working Paper Series may be downloaded free of charge at: www.wdi.bus.umich.edu

CURRENT AS OF 1/10/03

\begin{tabular}{|c|c|c|}
\hline Publication & Authors & Date \\
\hline $\begin{array}{l}\text { No. 524: Official Regulations and the Shadow Economy: A Labour } \\
\text { Market Approach }\end{array}$ & Maxim Bouev & Dec. 2002 \\
\hline No. 523: Children at Risk: Infant and Child Health in Central Asia & Cynthia Buckley & Jan. 2003 \\
\hline No. 522: Wages and International Rent Sharing in Multinational Firms & $\begin{array}{l}\text { John W. Budd, Jozef Konings and } \\
\text { Matthew J. Slaughter }\end{array}$ & July 2002 \\
\hline $\begin{array}{l}\text { No. 521: Gross Job Flows in Ukraine: Size, Ownership and Trade } \\
\text { Effects }\end{array}$ & $\begin{array}{l}\text { Jozef Konings, Olga Kupets and } \\
\text { Hartmut Lehmann }\end{array}$ & Dec. 2002 \\
\hline $\begin{array}{l}\text { No. 520: Entrepreneurial Networking in China and Russia: Comparative } \\
\text { Analysis and Implications for Western Executives }\end{array}$ & Bat Batjargal & Dec. 2002 \\
\hline $\begin{array}{l}\text { No. 519: Agriculture and Income Distribution in Rural Vietnam under } \\
\text { Economic Reforms: A Tale of Two Regions }\end{array}$ & $\begin{array}{l}\text { Dwayne Benjamin and Loren } \\
\text { Brandt }\end{array}$ & Mar. 2002 \\
\hline $\begin{array}{l}\text { No. 518: Property Rights, Labour Markets, and Efficiency in a } \\
\text { Transition Economy: The Case of Rural China }\end{array}$ & $\begin{array}{l}\text { Dwayne Benjamin and Loren } \\
\text { Brandt }\end{array}$ & Mar. 2002 \\
\hline $\begin{array}{l}\text { No. 517: Bank Discrimination in Transition Economies: Ideology, } \\
\text { Information or Incentives? }\end{array}$ & Loren Brandt and Hongbin Li & Oct. 2002 \\
\hline $\begin{array}{l}\text { No. 516: Ex-ante Evaluation of Conditional Cash Transfer Programs: } \\
\text { The Case of Bolsa Escola }\end{array}$ & $\begin{array}{l}\text { François Bourguignon, Francisco } \\
\text { H. G. Ferreira and Phillippe G. } \\
\text { Leite }\end{array}$ & Sep. 2002 \\
\hline No. 515: Missed Expectations: The Argentine Convertibility & $\begin{array}{l}\text { Sebastian Galiani, Daniel } \\
\text { Heymann and Mariano Tommasi }\end{array}$ & Nov. 2002 \\
\hline $\begin{array}{l}\text { No. 514: Job Reallocation and Productivity Growth under Alternative } \\
\text { Economic Systems and Policies: Evidence from the Soviet Transition }\end{array}$ & J. David Brown and John S. Earle & Nov. 2002 \\
\hline $\begin{array}{l}\text { No. 513: Cross-Border Trading as a Mechanism for Capital Flight: } \\
\text { ADRs and the Argentine Crisis }\end{array}$ & $\begin{array}{l}\text { Sebastian Auguste, Kathryn M.E. } \\
\text { Dominguez, Herman Kamil and } \\
\text { Linda L. Tesar }\end{array}$ & Nov. 2002 \\
\hline $\begin{array}{l}\text { No. 512: Embracing the Market: Entry into Self-Employment in } \\
\text { Transitional China, } 1978-1996\end{array}$ & Xiaogang $\mathrm{Wu}$ & Sep. 2002 \\
\hline $\begin{array}{l}\text { No. 511: Opening the Capital Account of Transition Economies: How } \\
\text { Much and How Fast }\end{array}$ & $\begin{array}{l}\text { Daniel Daianu and Radu } \\
\text { Vranceanu }\end{array}$ & Sep. 2002 \\
\hline $\begin{array}{l}\text { No. 510: Bridging "the Great Divide": Countering Financial Repression } \\
\text { in Transition }\end{array}$ & Patrick Conway & May 2002 \\
\hline $\begin{array}{l}\text { No. 509: Change the Regime - Change the Money: Bulgarian } \\
\text { Banknotes, 1885-2001 }\end{array}$ & Adrian E. Tschoegl & May 2002 \\
\hline $\begin{array}{l}\text { No. 508: Differential Rewards to, and Contributions of, Education in } \\
\text { Urban China's Segmented Labor Markets }\end{array}$ & $\begin{array}{l}\text { Margaret Maurer-Fazio and Ngan } \\
\text { Dinh }\end{array}$ & June 2002 \\
\hline $\begin{array}{l}\text { No. 507: Balassa-Samuelson Effect in Transition Economies: The Case } \\
\text { of Slovenia }\end{array}$ & Boštjan Jazbec & Oct. 2002 \\
\hline $\begin{array}{l}\text { No. 506: Explaining Gender Differences in Unemployment with Micro } \\
\text { Data on Flows in Post-Communist Economies }\end{array}$ & $\begin{array}{l}\text { Jana Stefanová Lauerová and } \\
\text { Katherine Terrell }\end{array}$ & Sep. 2002 \\
\hline No. 505: Bank Performance in Transition Economies & $\begin{array}{l}\text { Steven Fries, Damien Neven and } \\
\text { Paul Seabright }\end{array}$ & Sep. 2002 \\
\hline $\begin{array}{l}\text { No. 504: Does the Balassa-Samuelson Hypothesis Hold for Asian } \\
\text { Countries? An Empirical Analysis using Panel Data Cointegration Tests }\end{array}$ & Imed Drine and Christophe Rault & Sep. 2002 \\
\hline No. 503: Job Growth in Early Transition: Comparing Two Paths & $\begin{array}{l}\text { Štěpán Jurajda and Katherine } \\
\text { Terrell }\end{array}$ & Aug. 2002 \\
\hline $\begin{array}{l}\text { No. 502: Job Creation, Destruction and Transition in Poland, 1988- } \\
\text { 1998: Panel Evidence }\end{array}$ & $\begin{array}{l}\text { John E. Jackson and Bogdan } \\
\text { Mach }\end{array}$ & June 2002 \\
\hline $\begin{array}{l}\text { No. 501: Competition, Innovation and Growth in Transition: Exploring } \\
\text { the Interactions between Policies }\end{array}$ & $\begin{array}{l}\text { Philippe Aghion, Wendy Carlin } \\
\text { and Mark Schaffer }\end{array}$ & Mar. 2002 \\
\hline No. 500: Women in the LAC Labor Market: The Remarkable 1990's & $\begin{array}{l}\text { Suzanne Duryea, Alejandra Cox } \\
\text { Edwards and Manuelita Ureta }\end{array}$ & June 2001 \\
\hline $\begin{array}{l}\text { No. 499: Human Capital, Growth and Inequality in Transition } \\
\text { Economies }\end{array}$ & Michael Spagat & July 2002 \\
\hline No. 498: Understanding Czech Long-Term Unemployment & $\begin{array}{l}\text { Štěpán Jurajda and Daniel } \\
\text { Münich }\end{array}$ & Aug. 2002 \\
\hline
\end{tabular}

